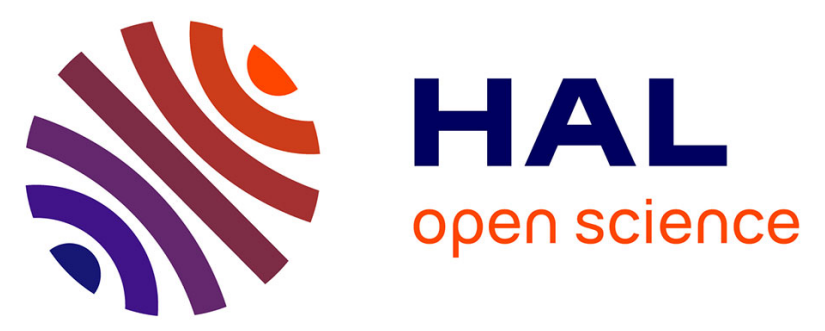

\title{
Travail dominical, usages du temps et vie sociale et familiale: une analyse à partir de l'enquête Emploi du temps
}

\author{
Jean-Yves Boulin, Laurent Lesnard
}

\section{- To cite this version:}

Jean-Yves Boulin, Laurent Lesnard. Travail dominical, usages du temps et vie sociale et familiale: une analyse à partir de l'enquête Emploi du temps. Economie et Statistique / Economics and Statistics, 2016, Travail et santé, 486-487, pp.149-182. 10.3406/estat.2016.10695 . hal-01401683

\section{HAL Id: hal-01401683 \\ https://hal-sciencespo.archives-ouvertes.fr/hal-01401683}

Submitted on 23 Nov 2016

HAL is a multi-disciplinary open access archive for the deposit and dissemination of scientific research documents, whether they are published or not. The documents may come from teaching and research institutions in France or abroad, or from public or private research centers.
L'archive ouverte pluridisciplinaire HAL, est destinée au dépôt et à la diffusion de documents scientifiques de niveau recherche, publiés ou non, émanant des établissements d'enseignement et de recherche français ou étrangers, des laboratoires publics ou privés.

\section{(1)(1) $\$(0)$}

Distributed under a Creative Commons Attribution - NonCommercial - ShareAlikel 4.0 


\title{
Travail dominical, usages du temps et vie sociale et familiale : une analyse à partir de l'enquête Emploi du temps
}

\author{
Jean-Yves Boulin * et Laurent Lesnard **
}

Les débats relatifs au travail dominical opposent, d'un côté, les tenants de la liberté de travailler sans contrainte, qui mettent en avant les gains de compétitivité de l'économie et les gisements d'emploi que recélerait l'ouverture des commerces le dimanche, et, de l'autre, à la fois les défenseurs, de moins en moins nombreux, d'un temps consacré à la sanctification et ceux qui prônent le maintien d'un temps commun consacré à la vie en société et à la famille. Les premiers invoquent l'évolution de la société, des modes de consommations, la compétition économique dans un monde globalisé tandis que les seconds font appel aux travaux socio-historiques, à la dimension socio-anthropologique du dimanche et à la nécessité d'en préserver la spécificité. D'un côté comme de l'autre, peu de référence est faite aux conditions de vie et de travail des salariés amenés à travailler le dimanche.

L'étude réalisée ici à partir de l'enquête Emploi du temps, bien que n'étant pas une étude d'impact du travail le dimanche à proprement parler, permet de comparer les usages du temps de ceux qui travaillent le dimanche et de ceux qui ne travaillent pas ce jour-là. Selon les estimations économétriques, travailler le dimanche va de pair avec une perte de sociabilité familiale et amicale et une diminution du temps de loisir allant au-delà de celles observées un jour de semaine et qui ne sont pas, en général, entièrement contrebalancées par le jour de repos compensateur. De plus, les salariés concernés par le travail le dimanche, c'est-à-dire par une forme de travail atypique, sont également ceux qui sont le plus concernés par des horaires de travail atypiques les jours de la semaine.

Codes JEL : J22, J81, Z13.

Mots clés : emplois du temps, travail dominical, horaires de travail, détermination des horaires de travail, sociabilité familiale, sociabilité amicale. 
$\mathbf{E}^{n}$ n 2011, selon l'enquête Emploi, 6,5 millions de salariés travaillaient le dimanche, dont 3 millions de façon habituelle (Vinck et Algava, 2012). À cela, il convient d'ajouter 1,6 million de non-salariés. La part des salariés concernés par le travail le dimanche s'est accrue de 9 points en vingt années, passant de $20 \%$ en 1990 à $29 \%$ en 2011 (ils étaient $18 \%$ en 1984). Ainsi que le signale le rapport Bailly (2013), si le travail dominical occasionnel demeure prépondérant (15,5\% des salariés), le travail dominical habituel est celui qui progresse le plus vite (13,2\% des salariés en 2011, soit une augmentation de plus de $30 \%$ depuis 1990) ${ }^{1}$.

Ainsi, près de $30 \%$ de la population active française serait concernée, de façon plus ou moins intense, par le travail le jour de la semaine consacré au jour de repos hebdomadaire par la loi de 1906. À travers des dérogations de droit, administratives ou conventionnelles, le travail dominical est majoritairement le fait de personnes qui assurent la sécurité des biens et des personnes ( $80 \%$ de celles qui œuvrent dans ce domaine sont concernées), qui travaillent dans le champ de la santé (60\% d'entre elles travaillent le dimanche) ou qui contribuent à la « continuité de la vie sociale » $(50 \%$ des salariés qui relèvent des secteurs du transport, de l'hôtellerie-restauration, des commerces, ou encore des activités socio culturelles et de loisirs sont concernés par le travail du dimanche, voir Vinck et Algava, 2012). Le poids de ces professions dans l'emploi total s'est certes accru ${ }^{2}$, expliquant partiellement, de façon mécanique, l'augmentation des salariés concernés par le travail dominical, mais celle-ci résulte également d'évolutions relatives à l'organisation des horaires de travail (développement de la flexibilité du temps de travail), aux pratiques professionnelles notamment dans le champ du commerce (élargissement des amplitudes horaires d'ouverture), aux modes de vie (croissance de la part des couples bi-actifs, mutation des habitudes de consommation et des comportements dans la sphère du hors travail), légitimées ou stimulées par la législation qui maintient le principe du repos dominical pour tous, tout en étendant le champ des dérogations. Ainsi, au-delà des secteurs déjà mentionnés, la possibilité de recourir au travail du dimanche a été ouverte aux centres d'appel ainsi qu'aux jardineries en 2005, aux commerces de détail d'ameublement en 2008, tandis que la loi Maillé du 10 août 2009 l'a étendue de plein droit aux zones touristiques et l'a autorisée pour les commerces, alimentaires ou non, situés dans les Puce (Périmètre d'usage de consommation exceptionnel), légitimant par là-même des pratiques préalablement illégales. Tandis que les magasins de bricolage obtenaient une dérogation de plein droit en 2014, la loi Macron (6 août 2015) a de son côté porté de cinq à douze les dimanches du maire et initié de nouvelles zones échappant aux restrictions relatives au travail dominical (cf. encadré 1). Les types d'activité visés par ces dérogations ont un double effet d'extension du nombre de salariés concernés

\footnotetext{
1. Ces chiffres doivent toutefois être considérés avec prudence, voir plus bas l'encadré 4.

2. Forte croissance en particulier de la permanence des services de santé et médicaux-sociaux (la part de ce secteur dans l'emplo total est passée de 8,6\% à 10,3\% entre 1990 et 2011), liée au vieillissement de la population, impliquant une hausse du travail dominical pour les aides soignant(e)s et les aides à domicile, dont le pourcentage travaillant le dimanche est passé respectivement de $18 \%$ à $29 \%$ et de $63 \%$ à $75 \%$ entre 1990 et 2011 . Voir le rapport Bailly (2013).
}

Encadré 1

\section{LA RÉGULATION DU TRAVAIL DOMINICAL EN FRANCE}

Depuis la loi du 13 juillet 1906, un salarié ne peut travailler plus de 6 jours par semaine : au moins un jour de repos par semaine ( $24 \mathrm{~h}$ auxquelles s'ajoute un repos quotidien de $11 \mathrm{~h}$ minimum) doit lui être accordé, la loi précisant que « dans l'intérêt du salarié, le repos hebdomadaire est donné le dimanche". Toutefois, dès sa promulgation la loi comportait de nombreuses dérogations, permanentes ou temporaires, soumises ou non à autorisation, applicables à l'ensemble du territoire ou à certaines zones précisément délimitées (Plus de 180 activités sont concernées par ces dérogations allant de la fabrication de produits alimentaires destinés à la consommation immédiate, aux établissements de bricolage (2014) en passant par les hôtels, cafés, restaurants ainsi que nombre d'activités liées à la santé et à la sécurité de même qu'à celles considérées comme indispensables à la continuité de la vie sociale (transports...)).

Ce texte de loi, n'a pratiquement pas subi de modifications jusqu'au début de la décennie 1980. Ce sont d'abord les activités industrielles qui ont été concernées par l'extension du travail dominical, notamment à travers la mise en place d'équipes de suppléance - dont l'activité est concentrée sur le week-end (1982) puis via l'extension des possibilités de travail en continu dont la mise en œuvre, d'abord limitée à des raisons techniques, a été justifiée par des raisons 
économiques (1987 puis 1993). La mise en œuvre de ces dérogations au repos dominical peut être opérée par voie conventionnelle (accord collectif étendu ou accord d'entreprise ou d'établissement). À défaut d'accord, la dérogation au repos dominical pour raisons technique ou économique, tout comme la mise en place d'équipes de suppléances sont soumises à l'autorisation de l'inspection du travail. La loi ne précise les contreparties que pour les travailleurs impliqués dans des équipes de suppléance dont la rémunération doit être majorée d'au moins $50 \%$ par rapport à celle qui serait due pour une durée équivalente effectuée selon l'horaire normal de l'entreprise.

S'agissant du secteur du commerce de détail, il convient de distinguer tout d'abord le commerce de détail alimentaire, qui a toujours fait l'objet de dérogations, et le commerce de détail non alimentaire dont l'ouverture dominicale était strictement encadrée. S'agissant du premier qui pouvait ouvrir le dimanche matin sans que les salariés soient volontaires et sans contreparties obligatoires, la loi Maillé a repoussé l'heure de fermeture obligatoire de $12 \mathrm{~h}$ à $13 \mathrm{~h}$ tandis que la loi Macron a amélioré la situation des salariés travaillant dans des établissements dont la surface de vente est supérieure à $400 \mathrm{~m}^{2}$ : ils doivent désormais bénéficier d'une rémunération augmentée au minimum de $30 \%$. Dans les nouvelles zones géographiques créées par les lois Maillé puis Macron (cf. infra), les commerces alimentaires qui ouvrent après $13 \mathrm{~h}$ sont soumis aux mêmes conditions que les autres commerces: volontariat obligatoire et accord collectif définissant les contreparties. De plus, la loi Macron stipule que dans les établissements dont la surface de vente est supérieure à $400 \mathrm{~m}^{2}$, les jours fériés travaillés peuvent être déduits, dans la limite de trois, des dimanches du maire.

Ces dimanches du maire (du préfet pour la ville Paris) qui concernent tous les commerces ont été portés de cinq à douze par la loi du 6 août 2015. Seuls les salariés volontaires ayant donné leur accord écrit peuvent être amenés à travailler le dimanche. Ils perçoivent une rémunération au moins doublée et doivent bénéficier d'un repos compensateur équivalent en temps.

Les lois Maillé du 10 août 2009, puis Macron du 6 août 2015 ont sensiblement modifié les conditions de mise en œuvre de l'article L. 3132-20 du code du travail qui prévoit que le préfet peut accorder une autorisation d'ouverture dominicale ne pouvant excéder trois ans, valable pour toute l'année ou à certaines périodes uniquement, à tout commerce dont il est établi que le repos simultané, le dimanche, de tous les salariés de cet établissement serait préjudiciable au public ou compromettrait le fonctionnement normal de cet établissement. Cette dérogation est désormais conditionnée d'une part à l'existence d'un accord collectif fixant les contreparties accordées aux salariés - à défaut par une décision unilatérale de l'employeur prise après avis du comité d'entreprise ou des délégués du personnel et approuvée par référendum organisé auprès des personnels concernés - d'autre part au volontariat des salariés concernés. Le préfet peut étendre la dérogation à l'ensemble des établissements de la même localité exerçant la même activité et s'adressant à la même clientèle. En revanche, si la majorité des établissements le demande, ces autorisations d'extension peuvent être retirées.

Enfin, si des zones géographiques ont toujours fait l'objet de dérogations, plus précisément les «communes et zones d'intérêt touristique et thermale" ainsi que les "zones touristiques d'affluence exceptionnelle ou d'animation culturelle permanente ", les lois Maillé et Macron en ont étendu le champ d'application, modifié les conditions de mise en œuvre et introduites de nouvelles. S'agissant des communes et zones touristiques et thermales, la loi Maillé avait élargi à tous les commerces la dérogation de droit auparavant limitée à ceux proposant des biens et services en lien avec le tourisme ou l'activité thermale. De son côté, la loi Macron a introduit pour ces zones le principe du volontariat - et la nécessité d'un accord collectif définissant les contreparties. Par ailleurs, la loi Maillé du 10 août 2009 avait instauré des " périmètres d'usage de consommation exceptionnelle (Puce) » dans lesquels les commerces pouvaient obtenir une dérogation du préfet sous réserve que les salariés soient volontaires et que les établissements concernés soient couverts par un accord collectif (interprofessionnel ou de branche ou d'entreprise ou d'établissement ou à défaut d'une décision unilatérale de l'employeur prise après avis du comité d'entreprise ou des délégués du personnel et approuvée par référendum organisé auprès des personnels concernés) fixant les contreparties (non définies) au travail dominical. Devenus «zones commerciales » de plein droit ces nouveaux concepts commerciaux peuvent, avec la loi Macron, désormais éclore dans des communes de plus de 100000 habitants alors qu'elles étaient limitées à celles supérieures à 1 million d'habitants dans la version Maillé (concrètement, Aix-Marseille, Lille et Bordeaux). Cette logique de l'extension du domaine du travail dominical portée par les deux lois trouve un nouveau champ d'application avec la création par la loi du 6 août 2015 de deux nouvelles zones géographiques dans lesquelles les commerces peuvent désormais ouvrir tous les dimanches (comme tous les autres jours de la semaine) et ce jusque minuit: les zones touristiques internationales (ZTI; au nombre de douze pour Paris par arrêté ministériel du $25 \mathrm{sep}-$ tembre 2015, tandis que l'on en dénombre six en province par arrêté ministériel du 5 février 2016) ainsi que certaines gares (liste définie par arrêté ministériel du 9 février 2016 qui comprend les six grandes gares parisiennes ainsi que 6 gares de province). Comme pour les autres zones géographiques concernées, le volontariat des salariés est requis tandis que l'ouverture des commerces est conditionnée à l'existence d'un accord collectif (de branche ou de groupe, ou d'entreprise ou d'établissement ou conclu à un niveau territorial) fixant les contreparties, sans que celles-ci, notamment salariales ou en termes de repos compensateurs, soient précisées. La loi du 6 août 2015 prévoit enfin que les établissements de moins de onze salariés puissent bénéficier de cette dérogation uniquement après décision unilatérale de l'employeur définissant les contreparties, dès lors que celles-ci ont été approuvées par la majorité des salariés. 
par le travail du dimanche et d'augmentation de la durée du travail prestée ce jour-là puisque les commerces concernés tendent à ouvrir toute la journée alors qu'auparavant la plupart des commerces (essentiellement alimentaires) n'ouvraient que la matinée.

L'objet de cet article est de porter attention à l'impact du travail dominical sur la vie familiale et sociale et plus généralement sur les usages du temps des actifs occupés concernés. De fait, dans le débat récurrent relatif à l'extension de l'ouverture dominicale, dans ce secteur, cette dimension est largement ignorée alors qu'elle est essentielle du double point de vue de la « protection des salariés et de (la) cohésion sociale $»^{3}$.

Dans une première partie, nous rappellerons succinctement quels sont les enjeux auxquels renvoie le débat sur le travail dominical. Ceux-ci sont avant tout culturels et se rapportent à la dimension anthropologique ainsi qu'à l'ancrage historique du dimanche. Ils sont également de nature économique, se référant aux effets potentiels sur l'emploi de l'extension de l'ouverture dominicale des commerces. Dans la mesure où la plupart des simulations relatives à ces effets utilisent les exemples étrangers (Artus et al., 2007 ; Bailly, 2013 ; Cette et al., 2014 ; Perrot, 2015), nous évoquons d'abord les principales évolutions intervenues au cours des deux dernières décennies dans quelques pays européens qui vont toutes dans le sens d'une extension des horaires d'ouverture des commerces. Les raisons fortement différenciées de ces extensions se ramènent à une opposition entre pays du nord et pays du sud de l'Europe. Nous présentons ensuite un panorama des travaux de simulation menés en France sur les effets sur l'emploi d'une plus grande facilité d'ouverture des commerces le dimanche. Enfin, nous soulignons que l'enjeu social, largement dépendant de la spécificité du dimanche, est souvent occulté dans les débats relatifs à l'extension du travail dominical, la question étant considérée comme résolue par le principe d'une augmentation de la rémunération.

La dernière partie est consacrée à l'exploitation des données de l'enquête Emploi du temps de 2009-2010 (EET par la suite, voir encadré 2) afin de mieux cerner l'impact du travail dominical sur les usages du temps et la sociabilité des personnes concernées. Le choix de l'EET, préférée ici à l'enquête Emploi, vient notamment $\mathrm{du}$ fait que la première permet de distinguer entre le travail dominical à domicile et le travail dominical hors du domicile, ce que ne permet pas la seconde (cf. infra). En travaillant à partir des carnets d'activités et en introduisant le critère d'une durée de travail supérieure à $2 h$, nous pouvons approcher de manière beaucoup plus fine la réalité du travail dominical en termes de personnes concernées (PCS, sexe, secteur d'activité, etc) et de ses impacts sur la sociabilité et les loisirs selon qu'il est exercé au domicile ou hors domicile. Une première section est consacrée à caractériser la spécificité du dimanche au regard des autres jours de la semaine s'agissant des activités de la vie quotidienne. Dans un deuxième temps, nous nous attachons à mieux qualifier le profil des personnes qui travaillent le dimanche, tant en termes de caractéristiques individuelles que de secteurs concernés, et surtout de conditions de travail: les salariés concernés cumulent des conditions horaires et statutaires particulièrement difficiles. Une dernière section est consacrée aux conséquences du travail dominical sur les usages du temps ainsi que sur la sociabilité familiale et amicale des salariés concernés, en tenant compte notamment de leur situation conjugale et de la composition de leur foyer.

\section{Le dimanche : un jour de rupture}

C e qui domine dans les travaux relatifs au dimanche, c'est l'approche socio-historique visant à retracer la genèse du dimanche comme jour de repos et de sanctification puis son évolution - le plus souvent conflictuelle entre le pouvoir séculier et l'église, entre protestantisme et catholicisme, entre employeurs et employés - vers un jour aux usages plus diversifiés (temps commun pour la fête, les jeux, la rencontre, le repos, le travail et la consommation, voir McCrossen, 2000 ; Beck, 1997 ; Cabantous, 2013 ; Perron, 2010 ; Dantec, 2008). Certains auteurs décrivent la façon dont se déroulait le dimanche aux différentes époques en s'appuyant notamment sur des romans et récits de voyages (Harline, 2007), convoquant également le registre populaire pour mettre en évidence les oppositions fortes qui peuvent exister quant à l'appréciation portée sur le dimanche et sur son vécu (Miller, 2008). D'autres travaux s'inscrivent dans une approche de nature plutôt socio-culturelle, visant à cerner, dans une perspective comparative mais également historique, la signification du dimanche (ou de son équivalent selon les cultures) au sein

3. "Le repos dominical est un principe essentiel en termes à la fois de protection des salariés et de cohésion sociale », lettre de mission du Premier ministre à Jean Paul Bailly (30 septembre 2013). 
du contexte hebdomadaire ainsi que les représentations qui lui sont attachées dans différentes aires culturelles (Zeruvabel, 1985 ; Rybczynski, 1991 ; Rinderspacher et al., 1994).

Rares sont en effet les sociétés qui n'ont pas institué un jour - ou une période plus longue - de rupture récurrent et régulier dans les rythmes d'activités. Appelé tabu dans les sociétés polynésiennes où il était chargé d'interdits, il se retrouve également dans la haute antiquité égyptienne (1200 avant notre ère) ou dans le calendrier babylonien «qui décrivait les septième, quatorzième, dix-neuvième, vingt et unième et vingt-huitième jours comme des «jours maléfiques » au cours desquels diverses activités étaient prohibées » (Rybczynski, 1991). Une des caractéristiques commune à ces jours « néfastes》 ou «maléfiques » pour certaines sociétés, ou au contraire mêlant dévotion, joie et festivités pour d'autres, était la prohibition du travail. Le sabbat juif et le dimanche chrétien ont prorogé cette pratique d'un jour prohibant de nombreuses activités, d'un jour s'inscrivant dans une logique de rupture par rapport aux autres jours de la semaine.

Nos dimanches modernes dont la pratique se retrouve dans de nombreuses autres aires géographiques que la nôtre (Rinderspacher et al., 1994), ont conservé la spécificité de ces jours qui ne ressemblent pas aux autres jours de la semaine et ce, en dépit de profondes mutations dans les régulations et les pratiques au cours de l'histoire (Beck, 1997 ; Cabantous, 2013).

Au cours du XXe siècle, avec l'augmentation du temps libre et la multiplication/diversification des pratiques de loisir, le dimanche est devenu pour la majorité de la population, un jour dédié au repos, à la vie familiale, aux loisirs, au tourisme... Avec le relâchement des contraintes

Encadré 2

\section{L'ENQUÊTE EMPLOI DU TEMPS 2010}

L'enquête Emploi du temps est une enquête par questionnaire dont l'objectif est de collecter des informations sur la vie quotidienne. Au questionnaire s'ajoute un carnet d'activités inspiré des journaux de bord maritime, comptes rendus chronologiques des données relatives à la navigation. Au lieu d'évaluer des durées d'activités abstraites hors de tout contexte, il est demandé aux personnes interrogées de décrire dans une grille d'emploi du temps avec leurs propres mots une ou plusieurs journées fixées par l'enquêteur. Les écueils des autoévaluations de durées sont ainsi évités puisque les personnes interrogées n'ont pas à s'approprier un système de codification d'activités et à fournir des durées. Le recueil des récits de vie quotidienne est favorisé par la structure chronologique du carnet des enquêtes Emploi du temps : les activités ne sont plus abstraites et déconnectées les unes des autres mais sont retranscrites telles qu'elles s'enchaînent au quotidien (Chenu et Lesnard, 2006). Les activités sont ensuite recodées selon des algorithmes ou à la main. Dans l'enquête Emploi du temps réalisée par l'Insee en 2009 et 2010, les activités décrites ont été résumées dans une nomenclature qui comporte 140 postes.

II est très rare de travailler sur un niveau si fin, sauf dans le cas de travaux sur des activités spécifiques (les repas par exemple, voir Saint Pol (2006)). Lorsque l'on travaille sur l'ensemble des activités quotidiennes, il est nécessaire de procéder à des regroupements. Celui que nous avons adopté s'inspire des pratiques nationales et internationales (Szalai, 1972). II distingue: le temps personnel (dormir, se laver, etc.), les repas, les activités professionnelles, les études, le travail domestique dont il est difficile de se passer au quotidien (préparer les repas, mettre la table, ménage, etc.), les semi-loisirs, c'est-à-dire des activités à mi-chemin entre le travail domestique et les loisirs (bricolage, jardinage, couture, tricot, etc.), les soins aux enfants, les loisirs et les transports.

La population couverte par l'analyse est celle des actifs en emploi (excepté le clergé) résidant en France métropolitaine. Nous avons utilisé les deux carnets journaliers des individus tirés au sort ainsi que ceux de leurs éventuels conjoints. Les résultats descriptifs ont été pondérés à l'aide de la variable de pondération pertinente (celle associée au carnet ou celle qui concerne le sous-échantillon qui a dû remplir un semainier) après avoir été normalisée (Ponthieux, 2015).

Depuis l'enquête de 1998-1999, les enquêtes Emploi du temps françaises comportent également un semainier. Le semainier est un carnet dans lequel est reporté, quart d'heure par quart d'heure, les plages travaillées pendant une semaine, chaque ligne représentant une journée. Tous les actifs occupés interrogés dans l'enquête n'avaient pas à remplir de semainier (ceux qui avaient à remplir un autre module sur les décisions dans la vie de couple en étaient exemptés). Le premier jour du semainier est le jour du carnet le plus proche du jour de la visite par l'enquêteur de l'Insee.

Dans tout le reste de cet article, une journée sera considérée comme travaillée hors ou au domicile quand elle contiendra deux heures au plus respectivement de travail hors domicile ou au domicile.

Les analyses de régression n'ont pas été pondérées, suivant en cela les recommandations de Winship et Radbill (1994). 
sociales et culturelles (l'office du dimanche, le déjeuner familial), avec les mutations des structures familiales, le dimanche est aussi devenu un jour caractérisé par une grande diversité de pratiques et d'activités. Toute l'histoire du dimanche en Europe occidentale et dans de nombreux pays culturellement proches atteste du lent basculement d'un temps libre contraint vers un temps libre ouvert à des choix multiples, largement dépendants toutefois des configurations familiales, des situations sociales et économiques, du genre et de l'âge des individus. Ce caractère polychrone (Hall, 1983) a été renforcé, durant les deux dernières décennies par le développement de la flexibilité du temps de travail qui tend à indifférencier les moments durant lesquels on travaille et ceux où l'on peut se livrer à d'autres activités. Ce contexte a cristallisé le débat relatif à l'ouverture des commerces le dimanche, non seulement en France où il est récurrent depuis la décennie 1980, mais également dans de nombreux autres pays européens.

\section{Les tendances relatives à l'ouverture des commerces dans l'Union européenne : une forte tendance à la libéralisation}

\begin{abstract}
À la différence de la France, nombre de pays européens (pays scandinaves et anglo-saxons), en dehors d'une législation relative au repos dominical des salariés, s'étaient dotés de règles relatives aux horaires d'ouverture des commerces, tant à l'échelle quotidienne (avec une définition stricte des horaires d'ouverture entre $8 \mathrm{~h}-9 \mathrm{~h}$ et $17 \mathrm{~h}-18 \mathrm{~h}$ aux Pays-Bas, au Danemark ou en Allemagne) qu'hebdomadaire (dimanche prohibé mais également, dans plusieurs de ces pays, le samedi après midi). Ce régime horaire très limité par rapport à un pays comme la France s'est avéré insoutenable face à l'insertion croissante des femmes dans l'emploi salarié et à la généralisation des couples bi-actifs.
\end{abstract}

Si la Suède a totalement libéralisé l'ouverture dominicale des commerces dès $1971^{4}$, ce n'est que durant la décennie 1990 que les autres pays ont progressivement procédé à un élargissement des horaires d'ouverture des commerces. Dès 1994, en Angleterre et au Pays de Galles puis au Pays-Bas, au Danemark et en Allemagne. Ces trois derniers pays ont d'abord procédé à une extension des horaires d'ouverture durant les jours de semaine ainsi qu'à la levée des restrictions relatives au samedi après midi avant d'assouplir de manière plus limitée qu'en Angleterre les possibilités d'ouverture des commerces le dimanche. En Allemagne, cet assouplissement est intervenu en 2006 (la loi fédérale recommande une limite à 4 dimanches par an mais laisse la décision aux länder qui, outre le nombre de dimanches autorisés, peuvent fixer les horaires d'ouverture : de fait, aucun dimanche en Bavière et 8 à Berlin). Aux Pays-Bas, où l'interdiction reste la règle, le conseil municipal peut, depuis 1996, décider que les commerces pourront ouvrir jusqu'à douze dimanches par an et prévoir des dérogations pour les commerces alimentaires.

Durant les années 2000, l'Espagne puis l'Italie ont élargi les possibilités d'ouverture dominicale des commerces. Le tableau 1 résume les évolutions relatives à la régulation de l'ouverture des commerces le dimanche pour un certain nombre de pays européens. Il laisse entrevoir une assez grande diversité dans les règles qui président à l'ouverture dominicale des commerces: celles-ci vont en effet de la liberté totale (Italie), à de sérieuses limites qui sont soit liées au nombre de dimanche durant lesquels les commerces peuvent ouvrir (Allemagne, Pays-Bas, Espagne, France), soit relatives à des conditions horaires spécifiques exprimées en fonction de la surface des commerces (Angleterre, Finlande, Allemagne). En revanche, dans presque tous les pays, les zones touristiques bénéficient d'un régime généralement très assoupli.

\section{Des effets incertains sur l'emploi}

$\mathbf{U}$ ne étude menée en 1992 concluait au mieux à un effet neutre sur l'emploi et, au pire, à des destructions d'emplois quel que soit le scénario retenu (Cette et al., 1992). Dans un contexte différent, puisque menée seize années plus tard, une étude du CREDOC (Moati et Pouquet, 2008) conduisait à des conclusions similaires : des destructions d'emploi dans le commerce alimentaire (6 800 à 16200 emplois détruits) et une légère création d'emploi dans le commerce non alimentaire (de - 5400 à +14 800). Toutes ces simulations économiques visent à mesurer la résultante entre un effet de cannibalisme (résultant du gain que tirent les commerces ouverts le dimanche au détriment

4. En pratique, seuls les commerces de quelques grandes villes ouvrent entre $12 \mathrm{~h}$ et $16 \mathrm{~h}$. 
Tableau 1

\section{Évolutions des régulations relatives à l'ouverture des commerces le dimanche} dans quelques pays européens

\begin{tabular}{|c|c|c|c|}
\hline Pays & Régime antérieur & $\begin{array}{c}\text { Année de } \\
\text { changement }\end{array}$ & Régime actuel \\
\hline Angleterre & "Sunday is closed» & 1994 & $\begin{array}{l}<280 \mathrm{~m}^{2}, \text { pas de restriction } \\
>280 \mathrm{~m}^{2} \text {, (max } 6 \mathrm{~h} \text { entre } 10 \mathrm{~h} \text { et } 18 \mathrm{~h} ; 12 \mathrm{~h}-18 \mathrm{~h} \text { pour les grands } \\
\text { magasins type Harrods) }\end{array}$ \\
\hline $\begin{array}{l}\text { Alle- } \\
\text { magne }\end{array}$ & $\begin{array}{l}\text { Fermé le dimanche } \\
\text { et } 3 \text { samedis après midi } \\
\text { par mois }\end{array}$ & $\begin{array}{l}1996 \\
2003 \\
2006\end{array}$ & $\begin{array}{l}\text { Ouverture possible tous les samedis jusqu'à } 16 \text { h } \\
\text { Aucune restriction à l'ouverture du samedi }(6 \text { h-20 h) } \\
\text { Loi Fédérale : la fermeture demeure la règle, mais les Länder peuvent } \\
\text { décider l'ouverture dans la limite de } 4 \text { dimanches par an. Actuellement } \\
\text { zéro en Bavière mais } 8 \text { à Berlin }\end{array}$ \\
\hline Pays- Bas & Fermé le dimanche & 2003 & $\begin{array}{l}\text { Ouverture possible jusqu'à } 12 \text { dimanches par an entre } 12-17 / 18 \mathrm{~h} \\
\text { (régulation échelon régions/villes) } \\
\text { Ouverture possible sans restriction dans les grandes villes sur décision } \\
\text { du conseil municipal }\end{array}$ \\
\hline Espagne & Fermé le dimanche (usage) & $\begin{array}{l}2000 \\
2003 \\
2012\end{array}$ & $\begin{array}{l}>300 \mathrm{~m}^{2} \text {, minimum de } 11 \text { dimanches par an } \\
\text { Régulation transférée aux provinces (généralement } 1 \text { dimanche par an } \\
+ \text { les } 4 \text { de décembre) } \\
\text { Liberté totale pour la province de Madrid ainsi que pour d'autres villes } \\
\text { touristiques (Valence, Saragosse, Palma de Majorque...) } \\
\text { Obligation pour autorités municipales d'autoriser les }<300 \mathrm{~m}^{2} \text { pour au } \\
\text { moins } 10 \text { dimanches et jours fériés par an. }\end{array}$ \\
\hline Finlande & Fermé le dimanche & $\begin{array}{l}1990 \\
1994 \\
1997 \\
2014\end{array}$ & $\begin{array}{l}\text { Ouverture limitée aux quatre dimanches précédant Noël } \\
\text { Extension à } 6 \text { autres dimanches } \\
<400 \mathrm{~m}^{2}: 12-21 \mathrm{~h} \\
\left.>400 \mathrm{~m}^{2}: \text { mai à août, } 12 \mathrm{~h}-18 \mathrm{~h} \text {; novembre et décembre } 12 \mathrm{~h}-21 \mathrm{~h}\right) \\
<400 \mathrm{~m}^{2} \text { : aucune restriction le dimanche } \\
>400 \mathrm{~m}^{2}: 12 \mathrm{~h}-18 \mathrm{~h} \text { toute l'année ; jusque } 21 \mathrm{~h} \text { à partir du } 3^{e} \text { dimanche } \\
\text { de novembre }\end{array}$ \\
\hline Italie & Fermé le dimanche & 2003 & $\begin{array}{l}8 \text { dimanches/an +tout le mois de décembre. } \\
\text { Régulation par les Régions et Communes (zones touristiques) } \\
\text { Aucune restriction (24/7) }\end{array}$ \\
\hline Belgique & $\begin{array}{l}\text { Aucune restriction } \\
\text { mais repos hebdomadaire } \\
\text { pour salariés le dimanche } \\
\text { (cf. France) }\end{array}$ & 2007 & $\begin{array}{l}9 \text { dimanches par an possibles (le gouvernement fédéral en fixe } 6 \text {, } \\
\text { les conventions collectives } 3 \text { ). Pas de restriction dans les zones } \\
\text { touristiques. }\end{array}$ \\
\hline France & $\begin{array}{l}\text { Commerces alimentaires } \\
\text { ouverts le dimanche matin } \\
\text { jusque } 12 \mathrm{~h} \text { (marchés, petits } \\
\text { commerces) }+3 \text { dimanches } \\
\text { du maire par an }\end{array}$ & $\begin{array}{l}1993 \\
2005 \\
2008 \\
2009 \\
2014 \\
2015\end{array}$ & $\begin{array}{l}\text { Dimanches du maire passent de } 3 \text { à } 5 \\
\text { Dérogation de plein droit pour les jardineries } \\
\text { Dérogation de plein droit pour les commerces de meubles } \\
\text { Champ des dérogations étendu : zones touristiques, tous les magasins } \\
\text { peuvent ouvrir de plein droit. Création des Puce } \\
\text { L'heure de fermeture des commerces alimentaires passe de } 12 \mathrm{~h} \text { à } 13 \mathrm{~h} \\
\text { Dérogation de plein droit pour les magasins de bricolage } \\
\text { Extension de } 5 \text { à } 12 \text { dimanches dérogatoires } \\
\text { Les Puce deviennent zones commerciales et sont banalisés (limite des } \\
\text { agglomérations concernées passe de } 1 \text { million à } 100 \text { 000 habitants) } \\
\text { Création des ZTI pouvant ouvrir de plein droit tous les jours y compris } \\
\text { les dimanches } \\
\text { jusqu'à minuit. Mêmes règles applicables à certaines gares } \\
\text { Généralisation du principe du volontariat et de la conditionnalité d'un } \\
\text { accord collectif }\end{array}$ \\
\hline Portugal & Fermeture des commerces & 2003 & $\begin{array}{l}\text { Pas de restriction pour les petits commerces qui peuvent ouvrir le } \\
\text { dimanche comme les autres jours }(6 \mathrm{~h}-24 \mathrm{~h}) \text {, mais régulation à l'échelle } \\
\text { de la municipalité } \\
\text { Grandes surfaces : fermeture dimanche après midi (ouverture } 8 \mathrm{~h}-13 \mathrm{~h} \text { ) } \\
\text { Grandes surfaces : } 6 \mathrm{~h}-24 \mathrm{~h} \text { (régulation par la municipalité) }\end{array}$ \\
\hline Danemark & Fermeture & $\begin{array}{l}2000 \\
2012\end{array}$ & $\begin{array}{l}\text { Ouverture possible } 9 \text { dimanches par an (10 h-17 h) } \\
\text { Libéralisation totale }\end{array}$ \\
\hline
\end{tabular}

Source : données collectées par les auteurs. 
de ceux qui restent fermés), défavorable à l'emploi, et un effet d'offre, favorable, en faisant des hypothèses sur la part des commerces qui ouvriraient le dimanche si les obstacles législatifs tombaient. D'autres hypothèses sont faites concernant les effets sur les salaires et les prix dans le secteur du commerce de détail, ainsi qu'au regard des réactions des branches amont (baisse des marges induisant une diminution de l'investissement et une augmentation des prix). Les études concluent en général à un effet négatif sur la productivité (diminution du nombre de clients par heure) ainsi qu'à un effet neutre ou marginal sur la croissance.

Un rapport du Conseil d'analyse économique (Artus et al., 2007) concluait à un effet positif sur l'emploi (entre $3 \%$ et $5 \%$ ) de l'ouverture dominicale des commerces. Les auteurs se fondaient sur des travaux menés dans d'autres pays dans lesquels la législation a été assouplie (Canada, USA, Pays-Bas). Ils omettaient toutefois de préciser que la situation antérieure de ces pays n'est pas comparable avec celle de la France. En effet, comment comparer l'impact d'une modification de la régulation des horaires d'ouverture aux Pays-Bas qui ont connu une extension durant les jours de la semaine (rappelons que les commerces fermaient à 17-18h avant 1996 les jours de semaine et plus tôt le samedi après-midi) et le dimanche, durant lequel pratiquement aucun commerce n'était ouvert, avec la situation française ? En effet, en France les commerces ferment entre 19 et $22 \mathrm{~h}$ en semaine selon le type de commerce et pratiquement tous les commerces alimentaires sont ouverts le dimanche matin. On comprend, dans ces conditions de contraintes fortes sur l'accessibilité des commerces, que la libéralisation des horaires d'ouverture ait provoqué une hausse de la consommation et des créations d'emplois ou une augmentation de la durée du travail dans le secteur du commerce. Les études mentionnées par les auteurs n'étaient pas de plus en mesure de distinguer entre les effets liés à l'élargissement des horaires en soirée et l'assouplissement des règles relatives au travail dominical.

Une étude plus récente (Cette et al., 2014), conclut à la création de 20000 emplois dans le commerce de détail français si dix dimanches supplémentaires étaient accordés. Les auteurs précisent toutefois qu'ils n'ont pas tenu compte des possibles effets de cannibalisme. Pourtant, en Italie, une évaluation menée par la Confesercenti e federstrade (fédération patronale du petit commerce) des effets de la libéralisation totale des horaires d'ouverture des commerces, aboutit, 18 mois après l'entrée en vigueur du décret Salva Italia (2012), à un bilan très négatif : 32000 entités commerciales disparues et 90000 emplois perdus sans toutefois que les effets liés à la dérégulation des horaires des commerces et ceux liés à la crise économique puissent être clairement distingués.

\section{Des impacts sociaux peu étudiés}

$\mathbf{O}$ $\mathrm{n}$ ne peut manquer d'être frappé par l'absence de travaux, en France tout au moins, s'attachant à approcher les conséquences du travail le dimanche sur les conditions de vie et de travail des salariés concernés. Le débat de société est essentiellement instruit par des sondages récurrents qui interrogent les Français sur leurs opinions relatives à l'ouverture des commerces le dimanche ou plus généralement au travail du dimanche. Quelques-uns toutefois dépassent ce niveau de généralité pour, par exemple, comparer les opinions de la population dans son ensemble à celle des salariés concernés par le travail du dimanche (Moati et Pouquet, 2008), ou circonscrire l'enquête à ceux qui sont concernés par le travail dominical (Reynié, 2009). D'une façon indirecte, ce type d'approche, dont les résultats indiquent une bien moindre appétence pour le travail dominical de la part des salariés qui le pratiquent, constitue un indicateur des effets du travail du dimanche sur leur vie familiale et sociale ainsi que sur leurs loisirs.

Les enquêtes Emploi du temps apportent des informations sur les conditions et les modalités du travail dominical ainsi que sur son impact sur les usages du temps et la vie familiale et sociale de ceux qui travaillent ce jour-là. Au Canada, ces enquêtes ont été mobilisées pour évaluer, dans un contexte de dérégulation du travail du dimanche (le Lord's day act qui interdisait le travail du dimanche a été aboli, à l'échelon fédéral, en 1985), l'impact de ce dernier sur les usages du temps du dimanche comparés à ceux de la semaine (Zuzanek et Smale, 1999). En comparant les données de 1981 et celles de 2005, les auteurs observent que les usages du temps du dimanche tendent à se rapprocher de ceux des jours de semaine (plus d'épisodes de travail, de shopping, de travail domestique et moins d'épisodes de temps libre), ce qui se traduit en termes de perceptions par un «profil émotionnel» (l'enchaînement des perceptions subjectives des différents moments de la journée) du dimanche se rapprochant de celui des jours de la semaine. 
Michelson (2010) de son côté s'est intéressé à l'impact de la dérégulation des horaires d'ouverture des commerces le dimanche sur la vie familiale et la pratique religieuse des canadiens. En mobilisant les données des enquêtes Emploi $d u$ temps, il montre une corrélation négative entre l'augmentation du temps passé à faire du shopping et le temps de dévotion religieuse et une corrélation positive de ce même temps avec le temps passé en famille. Il montre également une corrélation négative entre le temps passé en emploi et le temps passé en famille. Ces travaux tendent donc à montrer que nous sommes en présence d'un jeu à somme nulle, puisque la sociabilité familiale de ceux qui ne travaillent pas ce jour là serait favorisée alors que celle de ceux qui travaillent le dimanche serait amputée. Mais l'auteur n'indique pas si la sociabilité familiale favorisée par le shopping est une augmentation absolue ou résulte d'un transfert de la sociabilité familiale d'une activité (jeu par exemple) vers une autre (shopping).

Le sociologue Michael Bittman (2005) a utilisé de son côté les enquêtes Emploi du temps australiennes pour analyser l'impact du travail du dimanche sur les usages du temps ainsi que sur la vie familiale et sociale des salariés concernés comparativement à ceux qui ne travaillent pas le dimanche. Il ressort de sa recherche que les premiers perdent des opportunités de vie familiale et sociale, de production de biens et de services dans les sphères domestique, sociale et civique et qu'ils ne peuvent pas rattraper ces opportunités lorsqu'ils ont du temps libre en semaine. Des résultats largement convergents avec ceux dégagés ici.

\section{Le dimanche, journée des loisirs partagés en famille ou entre amis}

$\mathbf{E}$ n matière d'activités quotidiennes, l'analyse de l'enquête Emploi du temps française de 2009-2010 confirme que le dimanche est avant tout le jour des loisirs (cf. figure I). En moyenne, la durée des activités récréatives loisirs hors télévision est de $3 \mathrm{~h} 45$ le dimanche, soit deux fois plus qu'un jour de semaine (1h45). La durée moyenne de loisir est également plus élevée d'une heure le dimanche que le samedi. Corrélativement, le dimanche est la journée de la semaine la moins travaillée : $11 \%$ des carnets de l'enquête Emploi du temps 2010 relatifs au dimanche comportent au moins deux heures de travail rémunéré à l'extérieur du domicile (contre $73 \%$ en semaine) et les journées de travail sont significativement plus courtes ( $5 \mathrm{~h} 15$ contre 7 h16 en semaine).

Le travail domestique et les repas durent également plus longtemps le dimanche qu'en semaine (30 minutes supplémentaires). Les soins aux enfants sont en revanche stables quel que soit le jour de la semaine. Il n'y a rien d'étonnant à cela puisqu'il ne faut pas confondre les soins aux enfants avec le temps passé avec les enfants. Si l'on restreignait les interactions avec les jeunes enfants aux seuls soins, nous en donnerions une estimation très appauvrie (cf. encadré 3 ). Les besoins des enfants en bas âge sont les mêmes quel que soit le jour de la semaine et il n'est donc guère surprenant que les soins aux enfants le dimanche soient les mêmes qu'en semaine, que ce soit un mercredi ou non ${ }^{5}$.

Tel que le laisse apparaître l'enquête Emploi $d u$ temps, les loisirs sont bien un moment de partage, d'abord avec les autres membres de la famille mais également avec les amis. Ces données infléchissent quelque peu la perspective tracée par Joffre Dumazedier (1962) qui voyait dans l'augmentation du temps libre la matrice de l'individu s'exonérant du poids des institutions, notamment familiales. Une telle orientation est sûrement intervenue depuis le début des années 1960 mais elle apparaît fortement contrebalancée par les valeurs qui demeurent attachées à la famille. De fait, la nature des liens familiaux a en effet profondément changé depuis les années 1960 avec la progressive symétrisation des rôles professionnels et familiaux des hommes et des femmes (Young et Willmott, 1973) ${ }^{6}$. Le lien familial repose de moins en moins sur la division du travail et de plus en plus sur la qualité des relations interpersonnelles (Berger et Kellner, 1964 ; Singly, 1996). Le temps passé ensemble en famille est ainsi l'un des piliers du lien familial contemporain et est en constante augmentation depuis qu'il est possible de le mesurer avec les enquêtes Emploi du temps (Lesnard, 2009). Bien entendu, il ne s'agit pas d'idéaliser la famille, tous les moments passés en famille ne sont pas toujours perçus positivement (Daly, 2001). Pour autant il semble important de souligner un changement social majeur qui est lié à la plus grande symétrie des places

\footnotetext{
5. Parmi les jours de semaines, nous avons systématiquement distingué le mercredi afin de tenir compte d'une éventuelle particularité de ce jour. En effet, en 2009-2010, il n'y avait pas école ce jour-là.

6. Cette symétrisation comporte néanmoins des limites, notamment la répartition toujours très inégale du travail domestique.
} 
occupées par les femmes et les hommes dans les sociétés contemporaines.

Comme en semaine, les activités familiales s'articulent le dimanche autour des repas et des loisirs. Les repas et, plus encore, les loisirs en famille durent plus longtemps le dimanche (cf. figure II). En moyenne, le temps de loisir dominical en famille s'élève à $55 \mathrm{mn}$ contre $22 \mathrm{mn}$ un jour de semaine (hors mercredi) et $46 \mathrm{mn}$ le samedi. Ce supplément de sociabilité familiale le dimanche par rapport à la semaine tient essentiellement à l'augmentation d'une trentaine de minutes des temps conjugal et parents-enfants. En revanche les temps mèreet père- enfant le dimanche ne diffèrent que très peu d'un jour de semaine (hors mercredi).

Les activités récréatives en compagnie de personnes connues sont également particulièrement élevées le samedi et plus encore le dimanche. Dans le contexte des loisirs, les personnes connues sont très certainement des amis ou des compagnons d'activités sportives ou culturelles. Le dimanche, les activités récréatives avec des amis approchent ainsi $90 \mathrm{mn}$ contre $28 \mathrm{mn}$ en semaine et $77 \mathrm{mn}$ le samedi. Si le temps de loisir en solitaire est également supérieur d'une demi-heure le dimanche par rapport à un jour de semaine, le temps de loisir le dimanche est très majoritairement $(70 \%)$ un temps partagé avec des proches et la famille, ce qui est confirmé par d'autres travaux (Castell, 2014).

\section{Qui travaille le dimanche?}

D our étudier les déterminants du travail le

\section{Figure I}

Durée moyenne des activités quotidiennes selon le type de journée
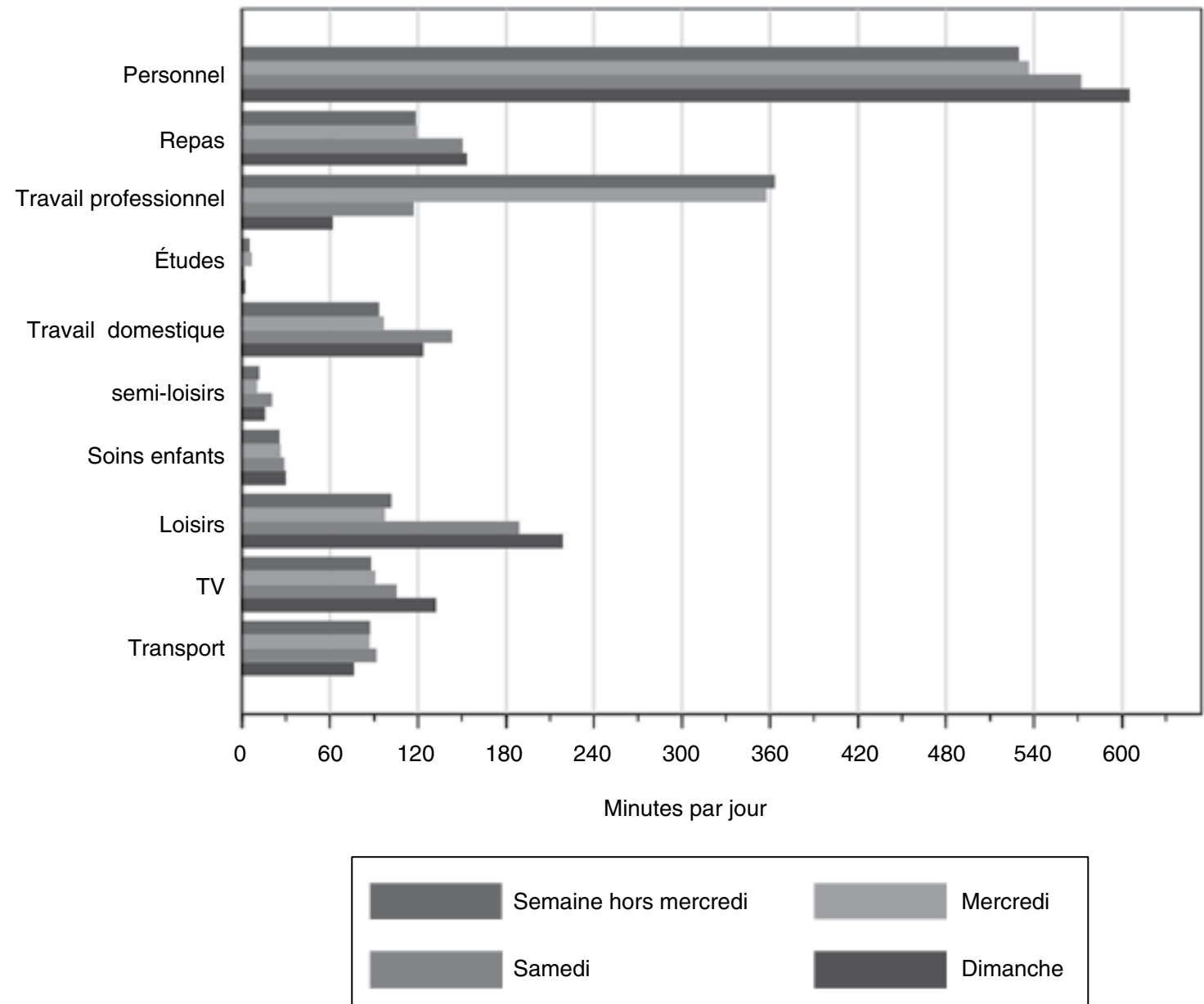

Lecture : la durée moyenne des activités de loisirs le dimanche est 3h45.

Champ : actifs occupés, France métropolitaine.

Source : enquête Emploi du temps 2009-2010 Insee. Calculs des auteurs. Résultats pondérés. 
posée dans le questionnaire de l'enquête Emploi du temps sur la fréquence du travail le dimanche, reprise de l'enquête emploi, nous préférons aborder la question des déterminants à partir des carnets de l'enquête Emploi du temps (cf. encadré 4). Nous distinguons deux types de travail dominical : à domicile ou sur le lieu de travail.

\section{Le rôle déterminant de la PCS et du secteur d'activité au regard de la probabilité de travailler le dimanche hors et à domicile}

Deux modèles de régression logistique ont été estimés (cf. tableau 2). Le premier explique le travail dominical hors domicile et le second à domicile (dans les deux cas c'est plus précisément la probabilité de travailler, hors ou à domicile, le dimanche deux heures ou plus). Comme l'on pouvait s'y attendre, hormis quelques exceptions sur lesquelles nous reviendrons, les travailleurs dominicaux hors et à domicile ont des profils très différents. Dans les deux cas, la profession et catégorie socio-professionnelle (PCS) apparaît le principal déterminant du travail dominical. Les travailleurs dominicaux hors domicile sont essentiellement les policiers et les militaires, les employés du public et les employés du commerce et des services. On notera que, fort logiquement, les cadres et les enseignants sont significativement sous-représentés dans cette catégorie de travail dominical, ne serait-ce qu'en raison de la fermeture de leur lieu de travail. Le secteur économique a été omis pour des raisons de taille d'échantillon, mais les secteurs de la santé, du transport ainsi que du commerce et des services apparaissent également fortement corrélés avec le travail dominical hors domicile.

Les travailleurs dominicaux à domicile présentent des profils très différents puisque, très logiquement, ils appartiennent à des catégories

Encadré 3

\section{LA CO-PRÉSENCE DANS LES ENQUÊTES EMPLOI DU TEMPS}

La catégorie des " soins aux enfants " ne mesure que les activités dont les enfants sont la finalité : hygiène quotidienne, surveillance des devoirs, lecture d'un livre, etc. De manière générale, la très grande majorité des catégories de la nomenclature des carnets d'emploi du temps porte sur des activités sans autre élément de contexte. Par exemple l'une des rares activités où le contexte est précisé est celle des repas pour lesquels la nomenclature distingue les repas à domicile seul ou avec une des personnes du ménage des repas à domicile avec au moins une personne hors ménage ou encore les repas sur le lieu de travail seul des repas sur le lieu de travail avec d'autres personnes (y compris du ménage). Pour les autres types d'activités, une partie de leur contexte est enregistrée dans d'autres rubriques du carnet : activité secondaire ("Faites-vous autre chose en même temps?"), lieu ou moyen de transport, personnes présentes («En présence de qui ?»), but de l'activité («Votre activité est dans un but ...»).

Ainsi, la rubrique «En présence de qui » du carnet permet d'avoir une idée des autres personnes présentes pour chaque activité décrite. Les modalités de réponse de l'enquête 2009-2010 étaient les suivantes: seul, avec votre conjoint, avec votre père ou votre mère, avec un ou des enfants du ménage, avec d'autres personnes du ménage et avec d'autres personnes connues. Le temps passé avec le conjoint sans les éventuels enfants permet d'enregistrer la "sociabilité conjugale" tandis que le temps passé avec le conjoint et les enfants capture lui la
« sociabilité parents-enfants " alors que le temps que chaque parent passe avec ses enfants sans l'éventuel autre conjoint permet de distinguer les " sociabilités mère- et père- enfants ». Ces modalités permettent d'éclairer plus finement et plus justement le temps passé auprès des enfants que les seules activités de soins aux enfants (Lesnard, 2009). Ainsi, dans l'enquête Emploi du temps de 1998-1999, le temps que les mères passent seules avec leurs enfants est composé en premier lieu de travail domestique, les soins n'arrivant qu'en deuxième position. Cela traduit le fait qu'au quotidien, les activités des mères combinent souvent plusieurs activités simultanément et l'information sur la co-présence permet de prendre en compte cette complexité. La prise en compte de cette information permet également d'avoir une idée plus juste du temps consacré aux enfants. Si on le restreint aux soins aux enfants, on sous-estime fortement le temps parental. Et ceci, tant pour les femmes, puisque la principale activité avec les enfants est le travail domestique devant les soins, et plus encore pour les hommes dont le temps passé avec les enfants, beaucoup plus faible que celui des mères, se compose principalement de loisirs et très peu de soins aux enfants.

La modalité "avec d'autres personnes que vous connaissez " est ambiguë puisqu'elle peut renvoyer tout autant à des collègues de travail qu'à des amis ou encore des voisins. Pour tenter de mesurer la sociabilité amicale, nous avons décidé de restreindre les activités réalisées avec des amis aux seuls loisirs. 
de travailleurs dont le travail ne dépend pas ou peu de leur lieu de travail : les professions intellectuelles et artistiques (22 fois plus de chances $^{7}$ de travail à domicile le dimanche que les employés administratifs) de même que les enseignants ( 15 fois plus de chances). Les cadres ont deux fois plus de chances de travailler le dimanche à domicile que les employés administratifs mais la faiblesse de l'échantillon ne permet pas de savoir si cette différence est statistiquement significative. Précisons encore une fois que notre indicateur est d'avoir travaillé deux heures ou plus.

Enfin, on peut distinguer une troisième catégorie de travailleurs dominicaux, ceux pour qui la différence entre le domicile et le lieu de travail a beaucoup moins de sens que pour les autres actifs : les agriculteurs, les artisans et les commerçants. Pour ces professions, pour beaucoup composées de travailleurs indépendants, le travail dominical est également bien souvent la règle, qu'il soit comptabilisé dans la catégorie hors ou à domicile.

À quelques exceptions près, les autres caractéristiques socio-démographiques n'ont pas d'effet sur la probabilité de travailler le dimanche hors ou à domicile. On peut noter une sous-représentation

7. Les chances sont la traduction de l'anglais odds et renvoient à un sens statistique précis lié aux rapports de chances, traduction de odds ratios. II n'y a donc aucun jugement de valeur dans l'usage de ce mot dans ce contexte très particulier.

\section{Figure II}

Différences de sociabilité entre le dimanche et un jour de semaine (hors mercredi)
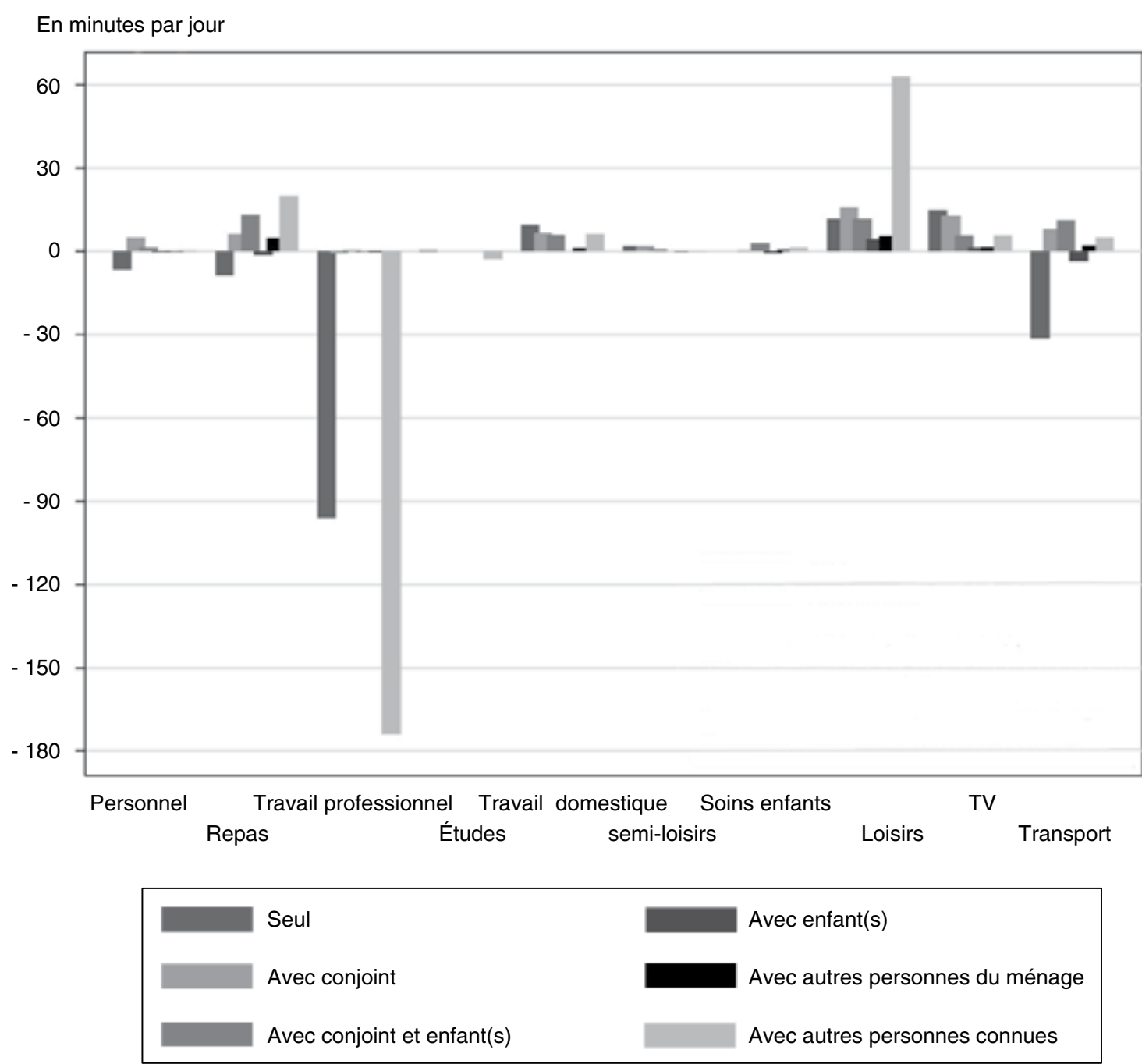

Lecture : en moyenne, les activités de loisirs avec le conjoint et au moins un enfant durent 10 minutes de plus le dimanche qu'un jour de semaine (hors mercredi).

Champ : actifs occupés, France métropolitaine.

Source : enquête Emploi du temps 2009-2010, Insee. Calculs des auteurs. Résultats pondérés. 
des actifs occupés âgés de 50 ans ou plus parmi les travailleurs dominicaux hors domicile (le coefficient associé à la tranche d'âge 60 ans et plus n'est cependant pas significatif). L'âge pourrait être une mesure indirecte de l'ancienneté dans l'emploi.

Les mêmes modèles appliqués au travail hors et à domicile le samedi donnent des estimations proches, mais de moindre ampleur ${ }^{8}$. Les déterminants du travail le week-end sont les mêmes, mais jouent plus fortement le dimanche.

Les probabilités prédites par les deux modèles économétriques permettent de mieux apprécier

8. Résultats disponibles sur demande auprès des auteurs.

\section{Encadré 4}

\section{LE TRAVAIL DOMINICAL DANS LES ENQUÊTES EMPLOI ET EMPLOI DU TEMPS}

Traditionnellement, les statistiques sur le travail dominical sont établies à partir des enquêtes sur l'emploi où une question sur la fréquence du travail dominical est posée systématiquement depuis 1990. Le premier problème de mesure du travail dominical par une telle question est celle du mélange du travail dominical au domicile (par exemple la préparation de cours pour les enseignants) et celui réalisé sur le lieu de travail. Le premier type de travail dominical est assez différent du second en raison de la plus grande liberté d'organisation du travail dans lequel il s'inscrit. En effet, contrairement au second qui implique de quitter son domicile et de s'organiser selon des plages temporelles durant lesquelles le salarié est à disposition de son employeur, le travail dominical à domicile est beaucoup plus flexible et peut s'organiser selon une autre logique (familiale ou amicale).

Le deuxième problème de mesure du travail dominical par la question posée dans l'enquête Emploi tient à la sensibilité de la réponse aux modalités proposées (Vinck et Algava, 2012). En effet, de 1990 à 2002, les modalités de réponse proposées étaient: habituellement, certains dimanches seulement et jamais. $\grave{A}$ partir de 2003, la modalité " certains dimanches seulement » a été remplacée par « occasionnellement ». Comme le soulignent Vinck et Algava, ce changement est loin d'être neutre puisque la formulation antérieure n'exclut pas une forme de régularité alors que le travail le dimanche occasionnel en semble plus éloigné. $\mathrm{Au}$ final, les auteures montrent que cela a eu pour effet d'augmenter le nombre de travailleurs dominicaux habituels et de diminuer ceux qui travaillent occasionnellement ce jour-là.

Avec l'enquête Emploi du temps, il est possible d'étudier le travail dominical de façon plus fine puisqu'elle permet de distinguer le travail professionnel à domicile et hors domicile. D'autre part, en raison de la surreprésentation des carnets le week-end dans l'enquête de 2010 (en comparaison avec les précédentes enquêtes emploi du temps), on observe un nombre suffisant de dimanches travaillés dans chacune de ces deux modalités.

Tableau 2

Régressions logistiques du travail le dimanche hors et à domicile ( $2 \mathrm{~h}$ et plus)

\begin{tabular}{|l|l|c|c|}
\hline \multirow{2}{*}{ Variables explicatives } & \multicolumn{2}{|c|}{ Travail rémunéré } \\
\hline Sexe & Homme & Hors domicile & Domicile \\
\hline Âge & femme & Réf. & Réf. \\
& $15-29$ & 0,818 & 1,025 \\
\hline & $30-39$ & 1,041 & 1,259 \\
& $40-49$ & $R e ́ f$. & $R e ́ f . ~$ \\
& $50-59$ & 0,879 & 0,879 \\
& 60 et plus & $0,582^{* *}$ & 1,158 \\
& Célibataire & 0,514 & 1,646 \\
\hline & PACS & $R e ́ f$. & $R e ́ f$. \\
& Mariage & 1,054 & 1,553 \\
& Veuvage & 0,796 & 1,483 \\
& Divorce & 0,869 & 0,510 \\
\hline
\end{tabular}


l'importance de la profession comme facteur explicatif principal du travail dominical hors et à domicile (cf. tableau 3 ). La probabilité de travailler le dimanche à domicile est très élevée pour les professions intellectuelles et artistiques ainsi que pour les enseignants. Les cadres ne travaillent qu'assez peu à domicile le dimanche selon le critère que nous avons retenu (deux

Tableau 2 (suite)

\begin{tabular}{|c|c|c|c|}
\hline \multirow{2}{*}{\multicolumn{2}{|c|}{ Variables explicatives }} & \multicolumn{2}{|c|}{ Travail rémunéré } \\
\hline & & \multirow{2}{*}{$\frac{\text { Hors domicile }}{\text { Réf. }}$} & \multirow{2}{*}{$\frac{\text { Domicile }}{\text { Réf. }}$} \\
\hline Statut conjugal & Sans conjoint & & \\
\hline & Vie en couple & 0,891 & 0,812 \\
\hline & En couple sans cohabitation & $0,413^{\star \star}$ & 1,716 \\
\hline Présence d'un enfant de moins & Oui & 1,413 & 1,028 \\
\hline de 3 ans & Non & Réf. & Réf. \\
\hline \multirow[t]{2}{*}{ Présence d'un enfant 3- 6 ans } & Oui & 1,084 & 0,709 \\
\hline & Non & Réf. & Réf. \\
\hline \multirow[t]{7}{*}{ Diplôme } & Sans & 1,077 & 0,883 \\
\hline & CEP BEPC & 1,182 & 0,855 \\
\hline & BEP CAP & 1,244 & 0,899 \\
\hline & Bac tech. & 0,655 & 1,480 \\
\hline & Bac général & Réf. & Réf. \\
\hline & $\mathrm{Bac}+2$ & 0,888 & 1,101 \\
\hline & Supérieur $\mathrm{Bac}+2$ & 0,596 & 1,696 \\
\hline \multirow[t]{2}{*}{ Contrat de travail } & CDD & 0,952 & $0,415^{\star}$ \\
\hline & $C D I$ & Réf. & Réf. \\
\hline \multirow[t]{2}{*}{ Indépendant } & Oui & 1,177 & $3,936^{\star \star \star}$ \\
\hline & Non (salarié) & Réf. & Réf. \\
\hline \multirow[t]{15}{*}{ PCS } & Agriculteur & $9,561^{\star \star \star}$ & $3,595^{\star}$ \\
\hline & Artisan, commerçant & $3,801^{\star \star \star}$ & 1,952 \\
\hline & Profession libérale & 2,384 & 2,502 \\
\hline & Cadre & $0,304^{\star \star}$ & 2,045 \\
\hline & Prof. Intellectuelle ou artistique & 0,880 & $22,26^{\star \star \star}$ \\
\hline & Enseignant & $0,379^{\star}$ & $15,69^{\star \star *}$ \\
\hline & Prof. Intermédiaire public & 0,998 & 1,636 \\
\hline & Prof. Intermédiaire privé & $0,440^{*}$ & 0,912 \\
\hline & Technicien & 0,544 & 0,737 \\
\hline & Employé administratif & Réf. & Réf. \\
\hline & Employé public & $2,435^{\star \star}$ & 0,732 \\
\hline & Police ou militaire & $3,819^{* \star *}$ & - \\
\hline & Employé commerce et services & $2,212^{\star *}$ & 1,450 \\
\hline & Ouvrier qualifié & 1,182 & 0,418 \\
\hline & Ouvrier non qualifié & 0,763 & - \\
\hline Constante & & $0,133^{\star \star \star}$ & $0,0131^{\star \star \star}$ \\
\hline $\mathrm{N}$ & & 2,948 & 2,739 \\
\hline Log- vraisemblance & & $-792,4$ & $-599,9$ \\
\hline Pseudo R2 & & 0,133 & 0,252 \\
\hline
\end{tabular}

Note : ${ }^{\star \star \star} \mathrm{p}<0,01 ;{ }^{* \star} \mathrm{p}<0,05 ;{ }^{*} \mathrm{p}<0,1$.

Lecture : selon le premier modèle, les chances de travailler plus de deux heures hors domicile le dimanche sont 2,2 fois plus élevées pour un employé du commerce et des services que pour un employé administratif.

Champ : actifs occupés, France métropolitaine.

Source : enquête Emploi du temps 2009-2010, Insee. Calculs des auteurs. Régressions non pondérées. 
heures ou plus), tout comme les employés du commerce et des services.

Le travail dominical hors domicile, est le plus fréquent pour les agriculteurs ( $42 \%)$ et les policiers ou militaires $(20 \%)$. La distinction domicile/lieu de travail n'est cependant pas toujours très claire pour les agriculteurs puisque c'est l'une des rares professions où cette délimitation est la moins marquée. Le cas des policiers ou des militaires s'explique aisément dans la mesure où ce sont des professions dont le but est d'assurer la sécurité des biens et des personnes de manière continue et pour qui le travail dominical est par conséquent une contrainte incontournable. La proportion de dimanches travaillés par ces professions permet donc de déterminer quel niveau de travail dominical permet d'assurer un service sans interruption. Assurer une activité professionnelle de manière continue implique un taux de travail dominical d'environ $20 \%$, autrement dit, de travailler un dimanche sur cinq.

Ce chiffre permet de mieux apprécier l'importance du travail dominical hors domicile pour les autres professions. Les conclusions qui peuvent être tirées de la modélisation économétrique de la probabilité de travail hors domicile sont très claires : en dehors des professions qui doivent assurer une activité continue, seuls les employés dans le commerce et les services sont concernés. En outre, la probabilité de travail dominical en dehors du domicile prédite par le modèle est très élevée pour ces professions (13\%), soit plus d'un dimanche sur huit. $\mathrm{Au}$ regard de notre problématique de l'impact de l'extension du travail du dimanche sur la vie quotidienne de ceux qui travaillent ce jour-là, l'ouverture des commerces et des services le dimanche apparaît donc cruciale.
Enfin, comme l'on pouvait s'y attendre, le travail dominical hors et au domicile ne concerne pas les mêmes personnes.

\section{Le travail dominical s'inscrit le plus souvent dans une organisation du travail hebdomadaire atypique}

Pour étudier l'articulation du travail dominical avec le travail à l'échelle de la semaine, nous reprenons ici la typologie des semaines de travail issue d'une étude de Sautory et Zilloniz (2015). L'utilisation des méthodes d'appariement optimal sur les semainiers leur permet d'identifier neuf types de semaines. Les semaines standard (44\% des semaines de travail) se composent de cinq journées standard. Les longues semaines (24\%) comportent le plus souvent de longues journées de travail, parfois également avec du travail le week-end. Les auteures ont identifié trois types de semaines décalées qui se composent de journées décalées le matin $(7 \%)$, en soirée $(5 \%)$ et la nuit (3\%). La particularité des semaines fragmentées (3\%) est d'être composées de journées de travail comportant de longues coupures entre les épisodes de travail. Enfin, les auteures identifient trois types de semaines partiellement travaillées: des semaines composées de demi-journées de travail $(4 \%)$, des semaines qui comportent plusieurs journées courtes $(4 \%)$ et des semaines avec peu de jours de travail (6\%).

De manière générale, le travail le dimanche s'inscrit dans des rythmes de travail hebdomadaires atypiques (typologie des semaines). Près d'une semaine de travail sur deux comportant des journées avec du travail de nuit est une semaine avec du travail le dimanche

\section{Tableau 3 \\ Probabilités prédites par les modèles de travailler le dimanche hors et à domicile pour quelques PCS}

\begin{tabular}{|l|c|c|}
\hline & \multicolumn{2}{|c|}{ En \% } \\
& À domicile & En dehors du domicile de travailler le dimanche \\
\hline Policiers, militaires & 0 & 21,3 \\
Cadres & 3,8 & 2,4 \\
Professions intellectuelles et artistiques & 30,1 & 6,6 \\
Enseignant(e)s & 23,3 & 3,0 \\
Employé(e)s commerce et service & 2,5 & 13,6 \\
\hline
\end{tabular}

Lecture : selon le modèle économétrique qui explique le fait d'avoir travaillé le dimanche hors du domicile, la probabilité de travail dominical s'élève à $21,3 \%$ pour les policiers et militaires.

Champ : actifs occupés, France métropolitaine.

Source : enquête Emploi du temps 2009-2010, Insee. Calculs des auteurs. Régressions non pondérées. 
(cf. figure III). La moitié des semaines fragmentées se caractérisent par du travail dominical. Plus d'une semaine sur cinq avec des journées décalées le matin ou en soirée comporte du travail le dimanche. Le travail le dimanche est également plus fréquent lorsque les personnes sont sur des régimes de longues semaines ou à l'inverse de semaines courtes. Le travail du dimanche est ainsi la manifestation à l'échelle de la semaine d'une organisation temporelle atypique du travail. Les horaires atypiques sont assumés principalement, à l'exception des longues journées, par les salariés peu qualifiés de l'industrie et plus encore des services (Lesnard, 2008). Les régressions logistiques et l'utilisation de la typologie des semaines réalisée par Olivia Sautory et Sandra Zilloniz permettent d'étendre ces résultats au travail le dimanche. Ce sont les mêmes salariés peu qualifiés de l'industrie et des services, qui disposent d'une faible autonomie temporelle, d'une prévisibilité limitée de leurs horaires de travail qui travaillent le dimanche hors de leur domicile. Un tel constat avait déjà été fait au Canada où une étude a montré que le travail le week-end était surtout le fait de salariés à temps partiel, en contrat temporaire, en horaires atypiques, saisonniers, peu couverts par les conventions collectives et exerçant dans les secteurs primaires et les services (Zeytinoglu et Cook, 2006).

Le travail le dimanche est ainsi le plus souvent le prolongement d'horaires atypiques caractéristiques pour ces travailleurs des jours de semaine ${ }^{9}$. La typologie permet de montrer en effet que la très grande majorité des types

9. Une semaine avec du travail le dimanche sur cinq s'inscrit dans le rythme hebdomadaire standard.

\section{Figure III \\ Proportion de dimanches travaillés (deux heures et plus) dans le semainier selon le type de semaine de travail}

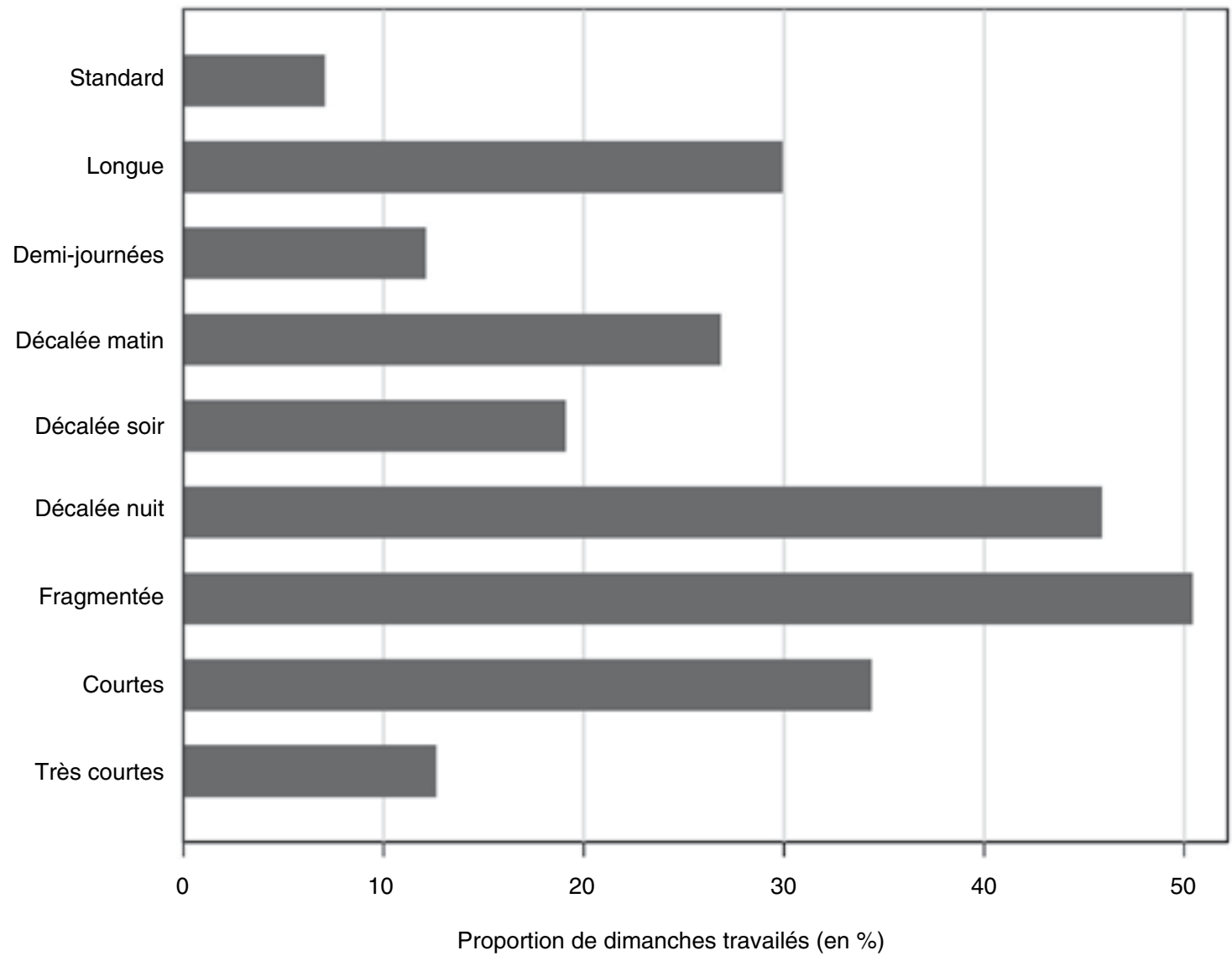

Lecture : 50 \% des semaines fragmentées comportent plus de deux heures de travail le dimanche.

Champ : actifs occupés ayant renseigné une semaine normale dans le semainier, France métropolitaine.

Source : Insee, enquête Emploi du temps 2009-2010, Insee. Article et calculs d'Olivia Sautory et Sandra Zilloniz et calculs des auteurs. Résultats pondérés. 
de semaines s'organise comme la répétition d'un type de journée de travail (à part pour les semaines où les types alternent). Par exemple, les semaines fragmentées sont la répétition de journées fragmentées, y compris le dimanche. Le travail le dimanche est donc doublement atypique puisque c'est un jour de la semaine atypique pour le travail et que les horaires de travail sont également très souvent atypiques. Si l'on introduit le type de semaine comme variable explicative ${ }^{10}$ dans le modèle explicatif du travail dominical hors domicile avec comme modalité de référence la semaine standard, alors tous les types de semaines atypiques, à l'exception des semaines composées de demi-journées, sont associés à des effets statistiquement significatifs (avec un niveau de confiance de $99 \%$ ). Quand ils sont significatifs, les coefficients indiquent tous des chances plus grandes de travailler le dimanche hors du domicile plus de deux heures. Les types de semaines qui sont le plus associés au travail le dimanche hors domicile sont les semaines décalées la nuit (11 fois plus de chances), celles qui sont fragmentées (9 fois plus de chances), ainsi que les semaines décalées en soirée ( 5 fois plus de chances). Le travail le dimanche hors domicile apparaît donc indissociable d'un rythme de travail hebdomadaire atypique, c'est-à-dire d'une semaine composée de journées de travail atypiques.

Comment expliquer ce phénomène ? S'agit-il de salariés qui, pour des raisons qui leur sont propres, choisiraient une organisation atypique de travail dans la semaine et le week-end? Par exemple, les étudiants afin de concilier leurs études et la nécessité de travailler, quand bien même le risque est grand que cela ne soit au détriment de leur réussite aux examens (Beffy et al., 2009) ? Question à laquelle il est difficile d'apporter une réponse définitive. Toutefois, une question posée aux salariés sur la détermination de leurs horaires de travail permet d'apporter des premiers éléments de réponse. De manière générale, seulement $13 \%$ des salariés déclarent déterminer librement leurs horaires de travail. À l'autre extrémité, près de deux salariés sur trois déclarent se voir imposer leurs horaires de travail par leur employeur. Si l'on restreint l'analyse aux travailleurs dominicaux, $4 \%$ d'entre eux estiment pouvoir organiser librement leurs horaires de travail (cf. tableau 4). Les horaires de travail, donc, très vraisemblablement, le fait de travailler le dimanche, sont donc imposés par l'employeur dans l'immense majorité des cas ( $86 \%$ des salariés qui travaillent le dimanche). L'explication vraisemblable selon laquelle seuls les salariés pour qui de tels horaires de travail ne posent pas de problème acceptent ces emplois doit être assortie d'un correctif. Les salariés concernés par le travail dominical sont en effet très souvent peu qualifiés comme nous l'avons vu précédemment; or le risque d'exposition au chômage de cette catégorie est particulièrement élevé : $9 \%$ pour les ouvriers et les employés contre 3,7\% pour les cadres (chiffres de l'Insee pour 2010).

\section{Les conséquences du travail du dimanche sur les usages du temps et la sociabilité}

\section{Les travailleurs dominicaux passent moins de temps avec leur proches autour d'activités récréatives}

L'analyse du carnet de l'enquête Emploi $d u$ temps 2010 montre que le travail le dimanche

10. Résultats disponibles sur demande auprès des auteurs.

Tableau 4

Détermination des horaires de travail des travailleurs dominicaux

\begin{tabular}{|l|c|c|c|}
\hline Eńtermination des horaires de travail & Dimanche non travaillé & Dimanche travaillé & Total \\
\hline Imposés & 62,1 & 86,2 & 64,3 \\
Variables avec plage fixe & 18,8 & 9,2 & 17,9 \\
Choix plusieurs horaires & 5,8 & 0,5 & 5,3 \\
Libres & 13,3 & 4,2 & 12,5 \\
Total & 100,0 & 100,0 & 100,0 \\
\hline
\end{tabular}

Lecture : 86,2 \% des salariés qui ont travaillé deux heures ou plus le dimanche d'après le carnet ont des horaires de travail imposés par leurs employeurs.

Champ : salariés, France métropolitaine.

Source : enquête Emploi du temps 2009-2010, Insee. Calculs des auteurs. 
(plus de deux heures de travail professionnel à l'extérieur du domicile) réduit le temps consacré à toutes les autres activités (cf. figure IV). Les loisirs sont les activités les plus touchées : ils durent en moyenne $2 \mathrm{~h}$ les dimanches travaillés contre un peu moins de $4 \mathrm{~h}$ lorsque le temps de travail dominical sur le lieu de travail est inférieur à deux heures. La réduction du temps de loisir s'accompagne d'une diminution de la sociabilité familiale : 15 minutes de loisir avec le conjoint en moins et 8 minutes de moins avec le conjoint et les enfants (cf. figure $\mathrm{V}$ ). Le temps père- et mère- enfant est moins affecté par le travail le dimanche ce qui s'explique en partie par le fait qu'il est plus caractéristique des jours de semaine que des dimanches. La sociabilité amicale est la plus affectée : $1 \mathrm{~h}$ de moins lorsque le dimanche est travaillé. Il ressort de ces observations que le temps hors travail d'un dimanche travaillé apparaît avant tout dédié à la famille.

\section{Les travailleurs dominicaux expriment le désir de passer plus de temps avec leurs proches}

Il est possible d'avoir une idée des conséquences subjectives du travail le dimanche en analysant les réponses apportées à une question posée à la fin du carnet d'emploi du temps : « $\mathrm{Si}$ vous pouviez changer cette journée, à quoi auriez-vous aimé consacrer plus de temps, moins de temps... ? ». Cette question était posée à propos de six activités : le sommeil, le travail ou les études, les tâches ménagères, la famille, les amis et les loisirs. Analyser ce genre de question demande beaucoup de précautions dans la mesure où, par exemple, les représentations sociales du temps passé en famille sont en règle générale positives (Daly, 1996). De fait, quasiment personne n'a déclaré avoir voulu passer un peu ou beaucoup moins de temps en

Figure IV

Activités le dimanche selon le nombre d'heures travaillées à l'extérieur du domicile

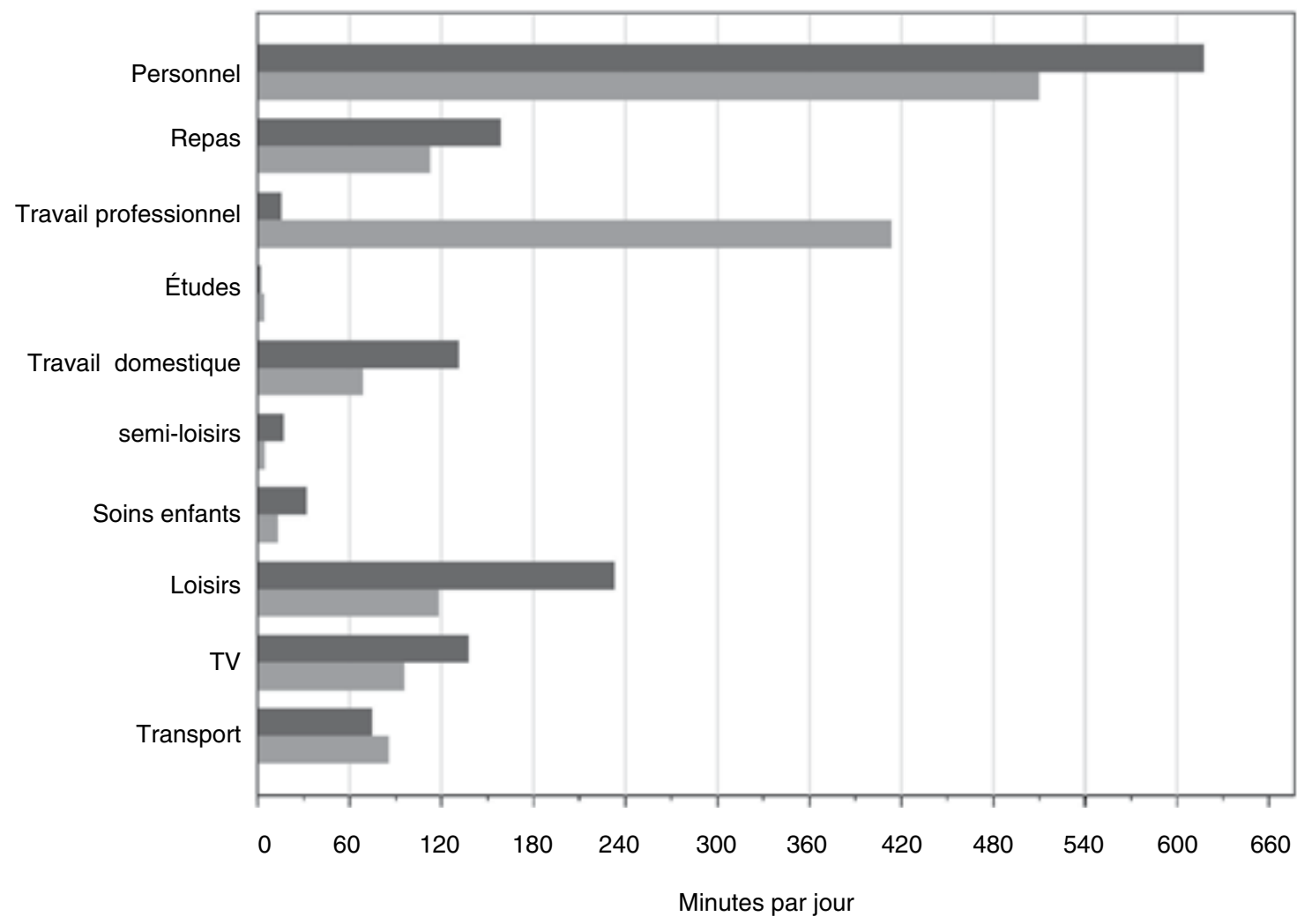

Moins de deux heures de travail

Deux heures de travail ou plus hors du domicile

Lecture : la durée moyenne des activités de loisirs le dimanche avec moins de deux heures de travail hors du domicile est de près de 240 minutes (4 heures).

Champ : actifs occupés, France métropolitaine.

Source : enquête Emploi du temps 2009-2010, Insee. Calculs des auteurs. Résultats pondérés. 
famille lorsque le jour du carnet comportait au moins deux heures de travail hors du domicile. Le biais de désirabilité sociale est confirmé, ce qui ne signifie pas pour autant que la question soit inexploitable.

En effet, il y avait deux possibilités de réponse positive et une modalité neutre ce qui permet de comparer leur distribution pour différents groupes de répondants : on peut en effet faire l'hypothèse que le biais de désirabilité sociale pousse dans un sens positif mais, à moins qu'il ne se cumule avec le biais acquiescement, il ne devrait pas conduire à répondre le plus positivement possible ${ }^{11}$. La figure VI présente la distribution des réponses pour un jour comportant au moins deux heures de travail hors domicile selon le jour de la semaine. Si les profils de la distribution des réponses sont sensiblement les mêmes en semaine et le mercredi, des différences importantes apparaissent avec les samedis travaillés et plus encore les dimanches. La proportion de réponses « beaucoup plus » passe ainsi de $30 \%$ en semaine à $40 \%$ le dimanche. Le taux de réponses neutres diminue également fortement, singulièrement le dimanche. Cumulées, les réponses positives atteignent

11. Autrement dit, le cumul des deux est possible mais pas systématique.

\section{Figure $\mathrm{V}$ \\ Différences de sociabilité entre un dimanche non travaillé et un dimanche avec plus de deux heures de travail à l'extérieur du domicile}

En minutes par jour

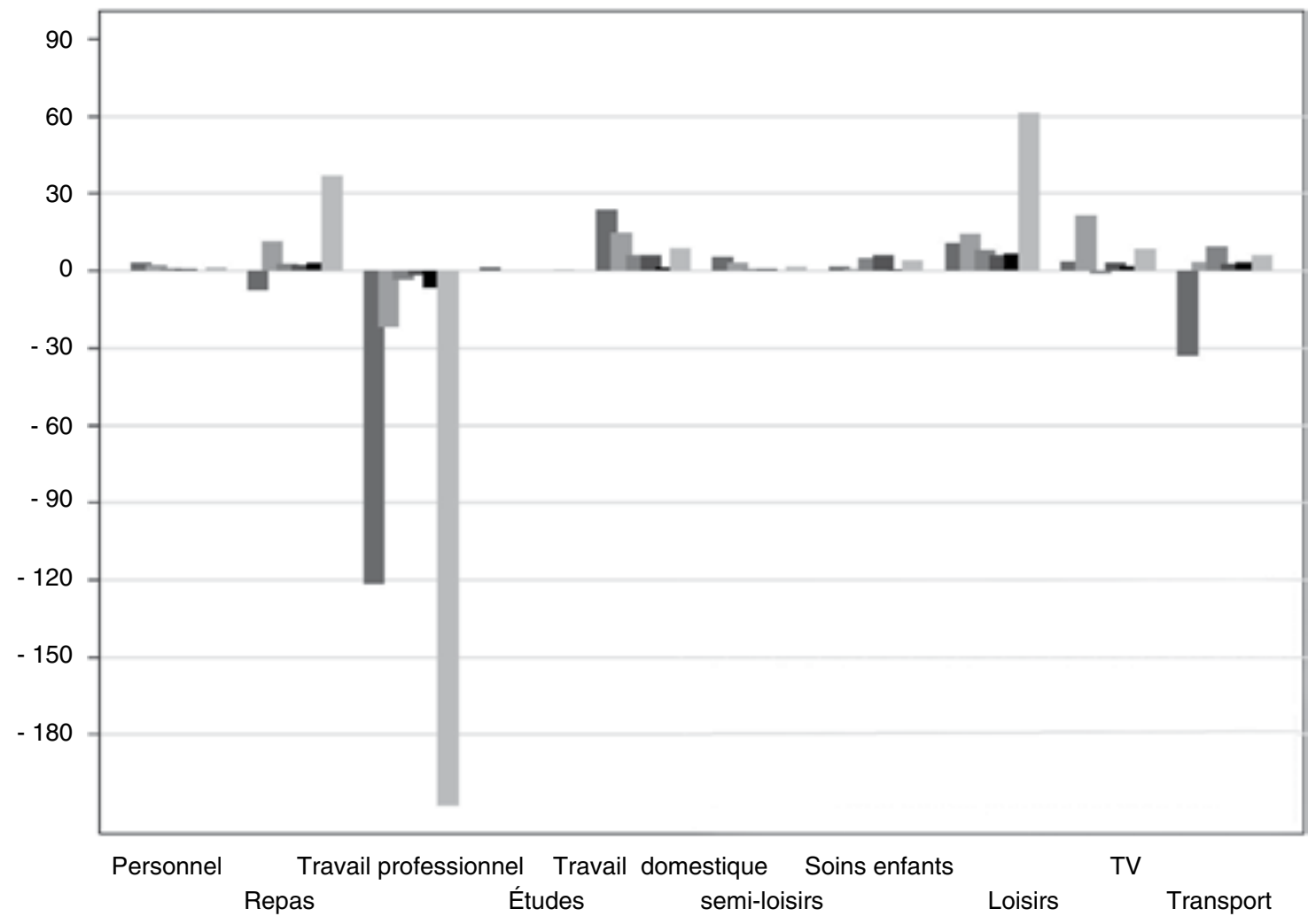

\begin{tabular}{|l|l|}
\hline Seul & Avec enfant(s) \\
\hline Avec conjoint & Avec autres personnes du ménage \\
Avec conjoint et enfant(s) & Avec autres personnes connues \\
\hline
\end{tabular}

Lecture : en moyenne, les activités de loisirs avec des amis durent $1 \mathrm{~h}$ de plus le dimanche non travaillé qu'un dimanche avec au moins deux heures de travail à l'extérieur du domicile.

Champ : salariés en emploi, France métropolitaine.

Source : enquête Emploi du temps 2009-2010, Insee. Calculs des auteurs. Résultats pondérés. 
$80 \%$ le dimanche. De telles différences apparaissent également pour le temps passé avec les amis mais dans des proportions moindres (résultats disponibles sur demande auprès des auteurs). Ces éléments laissent à penser que, indépendamment de la désirabilité sociale, les travailleurs du dimanche perçoivent négativement le coût en termes de sociabilité familiale de leurs activités professionnelles ce jour-là.

Le travail le dimanche réduit à la fois les loisirs et le temps passé en famille, c'est-à-dire ce qui fait la spécificité du dimanche. Cependant, une journée de travail en semaine limite également nécessairement les loisirs et le temps familial. Autrement dit, pour aller plus loin, il s'agit de savoir si le travail le dimanche a les mêmes conséquences sur les loisirs et la sociabilité familiale et amicale que le travail un jour de semaine. Le travail le dimanche s'accompagne d'un jour non travaillé en semaine et l'on peut également s'interroger sur le report de la sociabilité perdue le dimanche sur cette journée de repos compensateur.

\section{Un modèle pour analyser toutes choses égales par ailleurs les conséquences du travail dominical sur les sociabilités amicales et familiales}

Pour répondre à ces questions, il faudrait être en mesure d'évaluer l'impact du travail le dimanche sur les usages du temps des salariés, ou, dit autrement, d'estimer l'effet causal du travail le dimanche sur les usages du temps. En théorie, plusieurs approches pourraient être mises en œuvre. Tout d'abord, s'appuyer sur les expériences quasi-naturelles, telles les réformes ou autres chocs. Néanmoins, dans le cas présent, l'enquête Emploi du temps de 2009-2010 n'a pas assez de recul dans le temps par rapport à la loi Maillé (aôut 2009) qui modifie effectivement en profondeur la réglementation du dimanche, pour être mobilisée dans cet objectif conjointement à l'enquête précédente de 1998-1999. Le recours à d'autres méthodes, utilisant par exemple des données de panel, n'est également pas possible. Dans ce contexte, les estimations

Figure VI

Souhait de passer plus ou moins de temps en famille un jour travaillé selon le jour de la semaine En \%
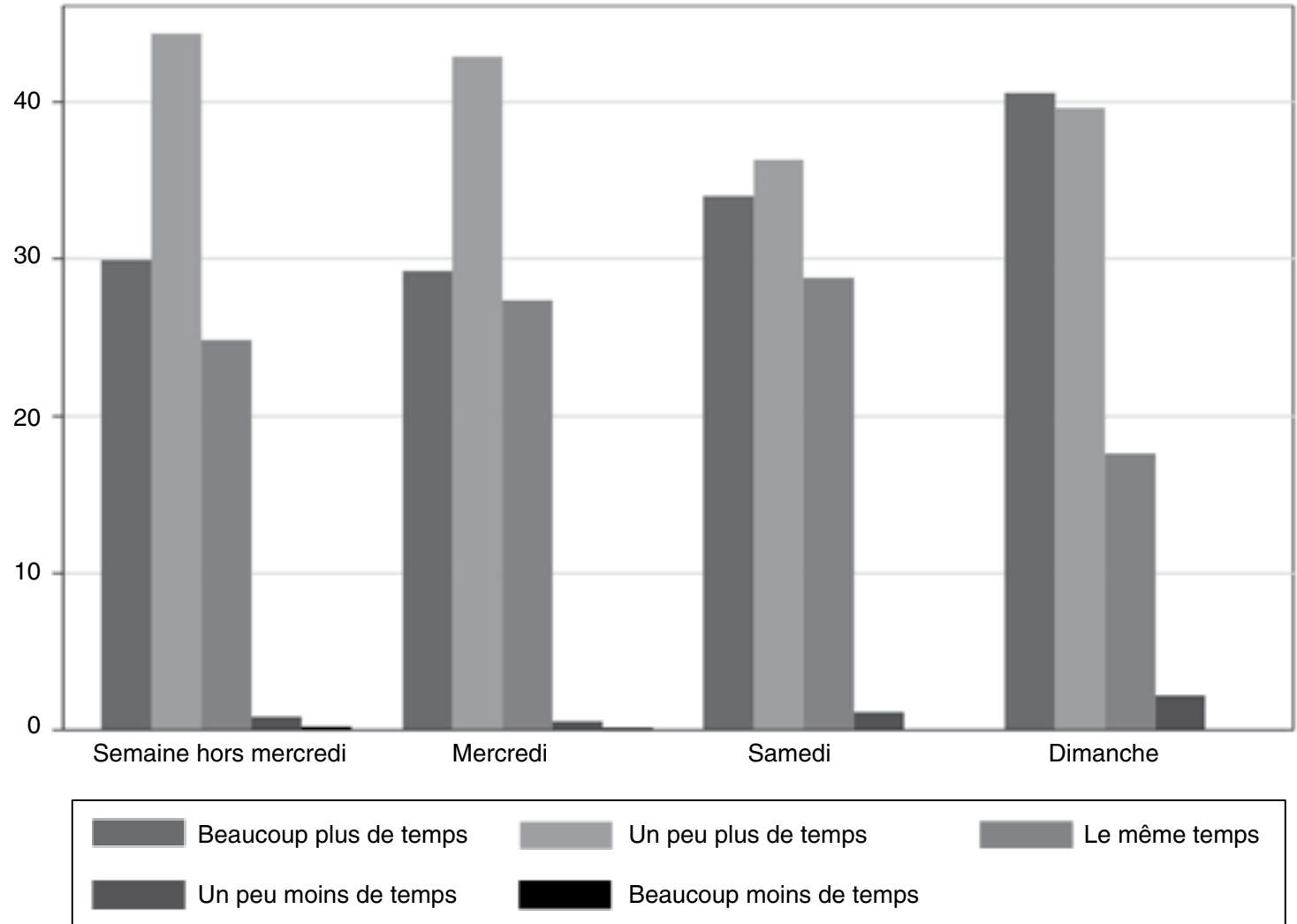

Lecture : $40 \%$ des personnes qui travaillent le dimanche auraient souhaité passer beaucoup plus de temps en famille. Champ : actifs occupés ne vivant pas seuls et ayant travaillé au moins deux heures hors de leur domicile, France métropolitaine. Source : enquête Emploi du temps 2009-2010, Insee. Calculs des auteurs. Résultats pondérés. 
économétriques en coupe, uniquement à partir de l'enquête Emploi du temps 2009-2010, qui est transversale, ne permettent pas une étude d'impact stricto sensu. Néanmoins, elles permettent de comparer les usages du temps des travailleurs concernés par le travail le dimanche aux autres une fois contrôlées les variables sociodémographiques et différentes caractéristiques de l'emploi. Ces estimations ne sont probablement pas exemptes de biais de sélection et d'endogénéité. Toutefois, des résultats de la section précédente, il ressort que le biais de sélection devrait être faible et ne devrait donc pas affecter massivement les estimations : les personnes qui travaillent le dimanche cumulent cette situation avec des contraintes d'horaires atypiques, d'où le caractère majoritairement subi de cette situation; ce ne sont pas des individus qui accepteraient de travailler le dimanche parce qu'ils sont spontanément peu demandeurs de sociabilité hors travail.

Nous avons estimé des régressions multiples $^{12}$. Les différentes composantes de la sociabilité familiale (temps conjugal, temps parents-enfants, temps mère-enfants et temps père-enfants) et les loisirs en présence d'amis, de même que la durée totale des loisirs (avec ou sans amis) sont expliqués par des variables sociodémographiques relatives à la situation familiale et professionnelle. Nous avons également introduit : deux indicateurs signalant que la journée du carnet était respectivement un jour de vacances scolaires ou un jour férié ; une variable catégorielle qui indique le jour du carnet (semaine hors mercredi - modalité de référence, mercredi, samedi ou dimanche) ; la durée du travail hors du domicile (en heures) et celle au domicile (en heures); la journée du carnet et une variable d'interaction avec ces deux dernières variables. La situation de référence est un jour de semaine ${ }^{13}$ (hors mercredi) non travaillé (durées du travail hors et à domicile nulles) hors vacances scolaires et non férié. L'introduction d'interactions entre variables explicatives permet de mesurer si les deux formes de travail dominical ont des conséquences différentes sur la sociabilité et les loisirs que le travail un autre jour de la semaine (voir l'exemple donné dans le tableau 5).

Une interaction s'interprète toujours comme un effet supplémentaire (lorsque le coefficient est statistiquement significatif). L'introduction d'une variable d'interaction permet de répondre exactement à la question suivante (cf. également encadré 5) : travailler hors domicile le dimanche a-t-il le même effet qu'un jour de semaine (interaction non significative) ou d'autres conséquences (interaction significative)?

Dans le cadre de cette modélisation, le coefficient d'interaction peut également s'interpréter comme une approximation de la mesure de l'éventuel report de sociabilité d'un dimanche

12. Ce sont les modèles les plus adaptés aux données d'emploi du temps (Stewart, 2012). En effet, les autres méthodes qui tiennent compte du fait que des durées ne peuvent pas être négatives (modèle Tobit ou régression gamma par exemple) donnent des résultats biaisés.

13. " Jour de semaine (hors mercredi) » signifie de fait « jour de semaine hors mercredi, samedi, dimanche». Cette convention est retenue dans le reste du texte.

Tableau 5

Interprétation des interactions

\begin{tabular}{|c|c|c|}
\hline Variables ou modalités & Variable d'interaction & Interprétation \\
\hline $\begin{array}{l}\text { Jour du carnet: } \\
\text { mercredi, samedi, } \\
\text { dimanche }\end{array}$ & & $\begin{array}{l}\text { La modalité de référence est un jour de semaine } \\
\text { (hors mercredi et week- end). Ces trois modalités } \\
\text { s'interprètent comme le surplus de loisirs ou de sociabilité } \\
\text { le mercredi, le samedi et le dimanche lorsqu'ils } \\
\text { ne sont pas travaillés }\end{array}$ \\
\hline $\begin{array}{l}\text { Nombre d'heures } \\
\text { de travail hors domicile }\end{array}$ & & $\begin{array}{l}\text { Permet de mesurer l'effet du nombre d'heures } \\
\text { de travail hors domicile un jour de semaine } \\
\text { (hors mercredi et week- end) }\end{array}$ \\
\hline Mercredi & Nombre d'heures de travail hors domicile & $\begin{array}{l}\text { Permet de mesurer l'effet additionnel du nombre d'heures } \\
\text { de travail hors domicile le mercredi par rapport à un autre } \\
\text { jour de semaine (hors mercredi et week- end) }\end{array}$ \\
\hline Samedi & Nombre d'heures de travail hors domicile & $\begin{array}{l}\text { Permet de mesurer l'effet additionnel du nombre d'heures } \\
\text { de travail hors domicile le samedi par rapport à un jour } \\
\text { de semaine (hors mercredi et week- end) }\end{array}$ \\
\hline Dimanche & Nombre d'heures de travail hors domicile & $\begin{array}{l}\text { Permet de mesurer l'effet additionnel du nombre d'heures } \\
\text { de travail hors domicile le dimanche par rapport à un jour } \\
\text { de semaine (hors mercredi et week- end) }\end{array}$ \\
\hline
\end{tabular}


travaillé sur la journée de repos compensateur en semaine. En effet, s'il y a bien une perte de sociabilité plus grande le dimanche qu'en semaine pour chaque heure travaillée, la question qui se pose est alors de savoir si le report $\mathrm{du}$ repos dominical en semaine s'accompagne du report de la sociabilité familiale et amicale qui a été perdue.

Le repos compensateur qui fait suite à un dimanche travaillé est par définition un jour de semaine sans travail. L'inverse n'est toutefois pas nécessairement vrai : une journée non travaillée un jour de semaine ne correspond pas nécessairement à une journée de repos compensateur d'un dimanche travaillé. En effet, ne pas travailler un jour en semaine peut renvoyer à des situations très variées : journée de congé ou de RTT, journée non travaillée en raison d'un temps partiel (qui peut être pris pour s'occuper de personnes dépendantes), journée de chômage technique et enfin journée de compensation pour du travail le dimanche.

Dans nos modèles, la situation de référence est une journée de semaine non travaillée (hors mercredi et week-end). Elle ne renvoie que dans un certain nombre de cas à une journée de repos compensateur. Il est important de souligner ce point car un jour de semaine non travaillé peut également être la conséquence de la volonté ou de la nécessité de passer du temps avec d'autres personnes. C'est par exemple le cas du quatre cinquième qui est souvent lié au fait que le mercredi était un jour sans école. Ce qui implique par ailleurs que les autres personnes concernées soient disponibles. Ainsi, une journée non travaillée en semaine prise en RTT pour participer à un voyage scolaire avec la classe de son enfant ou bien une autre journée consacrée aux soins et aux courses d'une personne âgée n'auront que peu à voir, en termes de sociabilité, avec une journée de repos compensateur imposée dans la semaine suite à un dimanche travaillé. La situation de référence renvoie donc à des situations qui, en termes de choix et de disponibilité des proches, peuvent être radicalement différentes au regard de leurs effets sur la sociabilité.

Dès lors, la situation de référence est, pour chaque modèle explicatif d'un type donné de sociabilité, une moyenne de toutes les situations qui viennent d'être évoquées pour expliquer l'absence de travail un jour de semaine. Par exemple, la sociabilité mère-enfants estimée par notre modèle pour un jour de semaine non travaillé (hors mercredi) est une moyenne entre journée de congé, JRTT, temps partiel (éventuellement pris pour passer plus de temps avec les enfants) et une journée de chômage technique ou de repos compensateur pour laquelle la latitude de choix est sans doute plus faible. Il est vraisemblable que la sociabilité est dans les premiers cas plus forte que dans les deux derniers.

Autrement dit, les sociabilités estimées dans les modèles pour une journée de semaine non travaillée surestiment très probablement celles qui se manifestent lors d'une journée de repos compensateur qui fait suite à un dimanche travaillé. Nous n'avons pas toutefois la possibilité d'estimer plus finement les effets des jours de repos compensateur. Il faut donc considérer que les sociabilités estimées par nos modèles pour une journée de semaine non travaillée donnent une approximation acceptable, bien qu'optimiste, des effets du repos compensateur.

\section{Encadré 5}

\section{L'INTERPRÉTATION DES INTERACTIONS DANS LES RÉGRESSIONS LINÉAIRES MULTIPLES}

L'introduction d'un coefficient d'interaction dans une régression linéaire multiple vise à affiner le lien entre une variable explicative et la variable à expliquer : l'effet de la première sur la seconde n'est plus direct mais dépend d'une autre variable. Par exemple, l'effet du nombre d'années d'études sur le niveau de revenu peut dépendre de l'ethnicité (Jaccard et Turrisi, 2003).

Un effet d'interaction rend l'analyse des résultats d'une régression moins aisée. Introduire une interaction doit donc être motivé théoriquement ou pour tester une hypothèse. C'est dans ce dernier cas de figure que nous nous trouvons puisque nous cherchons une réponse à la question suivante : est-ce qu'une heure de travail a les mêmes conséquences pour les différents temps de loisir et de sociabilités familiales et amicales le dimanche qu'un jour en semaine ? Retraduite en termes économétriques, I'hypothèse revient donc à tester le fait que l'effet du nombre d'heures de travail sur les loisirs et les sociabilités n'est plus direct mais dépend du jour de la semaine. 
Sous une telle hypothèse, l'effet du repos compensateur peut être évalué en comparant deux configurations :

1. Configuration de référence: la sociabilité un dimanche non travaillé (repos hebdomadaire) à laquelle s'ajoute la sociabilité nette (du temps de travail pendant $\mathrm{x}$ heures) d'un jour de semaine travaillé (hors mercredi et week-end) ;

2. Dimanche travaillé avec journée de repos compensateur en semaine: la sociabilité un jour de semaine (hors mercredi et week-end) non travaillé (repos compensateur) à laquelle s'ajoute la sociabilité nette (du temps de travail pendant $\mathrm{x}$ heures) d'un dimanche travaillé.

La sociabilité nette d'un jour de semaine travaillé est composée de la sociabilité un jour de semaine non travaillé moins la perte de sociabilité par heure de travail. De la même manière, la sociabilité nette d'un dimanche travaillé est la sociabilité d'un dimanche non travaillé de laquelle on soustrait la perte de sociabilité pour chaque heure travaillée. Autrement dit, les termes de la comparaison précédente peuvent être reformulés de la manière suivante :

\section{Configuration de référence $=$}

sociabilité un dimanche non travaillé

+ sociabilité une journée de semaine non travaillée

- sociabilité perdue par heure de travail un jour de semaine

\section{Dimanche travaillé avec journée de repos compensateur en semaine $=$}

sociabilité une journée de semaine non travaillée

+ sociabilité un dimanche non travaillé

- sociabilité perdue par heure de travail un dimanche

Par rapport à la situation de référence, les effets sur les sociabilités du travail dominical compensés par une journée de repos compensateur se réduisent donc à la différence entre la perte de sociabilité par heure de travail le dimanche et celle qui est perdue pour chaque heure travaillée un jour de semaine. Autrement dit, l'effet de la journée de repos compensateur est mesuré par le coefficient d'interaction entre la journée de la semaine et le nombre d'heures de travail. Il peut donc être interprété d'une nouvelle façon, comme la mesure de l'effet de la journée de repos compensateur. On peut distinguer trois cas :

1. L'interaction n'est pas significativement différente de zéro : cela revient à dire que les deux pentes sont égales, donc que la journée de repos compensateur permet de récupérer exactement la sociabilité perdue en travaillant le dimanche ; par ailleurs, la sociabilité perdue le dimanche est la même qu'en semaine ;

2. L'interaction est significativement différente de zéro et négative : la journée de repos compensateur ne permet pas de contrebalancer complètement la sociabilité perdue en travaillant le dimanche. La perte de sociabilité non compensée s'élevant alors au nombre d'heures travaillées multiplié par le coefficient d'interaction; par ailleurs, chaque heure de travail le dimanche diminue plus la sociabilité qu'un jour de semaine.

3. L'interaction est significativement différente de zéro et positive : la journée de repos compensateur permet de gagner plus que la sociabilité perdue en travaillant le dimanche, soit au total une différence nette qui correspond au nombre d'heures travaillées multiplié par le coefficient d'interaction ; par ailleurs, la sociabilité perdue le dimanche pour chaque heure travaillée est moindre par rapport à un jour de semaine.

\section{Le travail réduit les sociabilités amicales récréatives et familiales davantage le dimanche qu'en semaine}

La qualité de l'ajustement des trois premiers et des deux derniers modèles (cf. tableau 6) est exceptionnelle pour des données d'emploi du temps dont la variance expliquée dépasse rarement $10 \%$ (Gershuny, 2000). Les quatre premiers modèles permettent de retrouver des résultats descriptifs déjà établis sur le temps familial (Lesnard, 2009). La sociabilité familiale dépend fortement de la présence d'enfants et de leur âge. Les enfants en bas âge (moins de 3 ans) et les jeunes enfants (3-6 ans) sont associés à une réduction du temps conjugal, plus exactement une conversion d'une partie du temps conjugal en temps parents-enfants, et à l'apparition de deux temps spécifiques : le temps mèreet père- enfants. Le temps père-enfants est très inférieur au temps mère-enfants et il augmente légèrement à mesure que les enfants grandissent alors que c'est le contraire pour les mères. En effet, le temps père-enfants est composé essentiellement de loisirs alors qu'il est composé de travail domestique et de soins aux enfants pour 
Tableau 6

Résultats des estimations des régressions multiples des temps conjugal, parents- enfants, mère- et père- enfants et loisirs avec d'autres personnes connues

\begin{tabular}{|c|c|c|c|c|c|c|c|}
\hline \multicolumn{2}{|r|}{$\begin{array}{l}\text { Variables } \\
\text { explicatives }\end{array}$} & $\begin{array}{l}\text { Temps } \\
\text { conjugal }\end{array}$ & $\begin{array}{c}\text { Temps } \\
\text { parents- } \\
\text { enfants }\end{array}$ & $\begin{array}{l}\text { Temps } \\
\text { mère- } \\
\text { enfants }\end{array}$ & $\begin{array}{l}\text { Temps } \\
\text { père- } \\
\text { enfants }\end{array}$ & $\begin{array}{l}\text { Loisirs } \\
\text { amis }\end{array}$ & $\begin{array}{c}\text { Loisirs } \\
\text { avec ou } \\
\text { sans amis }\end{array}$ \\
\hline Statut conjugal & $\begin{array}{l}\text { Sans conjoint } \\
\text { Vie en couple } \\
\text { Vie en couple sans coha- } \\
\text { bitation }\end{array}$ & $\begin{array}{c}\text { Réf. } \\
-217,2^{\star \star \star}\end{array}$ & $\begin{array}{c}\text { Réf. } \\
-118,8^{\star \star \star}\end{array}$ & $\begin{array}{l}85,46^{\star \star \star} \\
\text { Réf. } \\
51,38^{\star \star}\end{array}$ & $\begin{array}{l}25,10^{* * *} \\
\text { Réf. } \\
2,750\end{array}$ & $\begin{array}{l}29,10^{\star * *} \\
\text { Réf. } \\
36,86^{\star * \star}\end{array}$ & $\begin{array}{c}189,8^{\star \star \star} \\
\text { Réf. } \\
27,41^{\star \star \star}\end{array}$ \\
\hline Nombre d'enfants & $\begin{array}{l}\text { Pas d'enfants } \\
1 \text { enfant } \\
2 \text { enfants } \\
3 \text { enfants ou plus }\end{array}$ & $\begin{array}{l}101,5^{\star \star \star} \\
\text { Réf. } \\
-30,89^{\star \star \star} \\
-34,95^{\star \star \star}\end{array}$ & $\begin{array}{c}\text { Réf. } \\
\text { 18,89*** } \\
4,688\end{array}$ & $\begin{array}{c}\text { Réf. } \\
19,84^{\star \star \star} \\
34,58^{\star \star \star}\end{array}$ & $\begin{array}{l}\text { Réf. } \\
8,837^{\star \star} \\
12,14^{\star \star}\end{array}$ & $\begin{array}{l}9,354^{* * *} \\
\text { Réf. } \\
2,305 \\
5,636^{\star}\end{array}$ & $\begin{array}{l}10,85^{\star * \star} \\
\text { Réf. } \\
-1,736 \\
-4,505\end{array}$ \\
\hline $\begin{array}{l}\text { Présence enfant } \\
\text { moins de } 3 \text { ans }\end{array}$ & $\begin{array}{l}\text { Oui } \\
\text { Non }\end{array}$ & $\begin{array}{c}-17,62^{\star \star \star} \\
\text { Réf. }\end{array}$ & $\begin{array}{c}24,57^{\star \star \star} \\
\text { Réf. }\end{array}$ & $\begin{array}{l}68,31^{\star \star \star} \\
\text { Réf. }\end{array}$ & $\begin{array}{l}\text { 17,59*** } \\
\text { Réf. }\end{array}$ & $\begin{array}{c}-11,25^{\star \star \star} \\
\text { Réf. }\end{array}$ & $\begin{array}{c}-26,65^{\star \star \star} \\
\text { Réf. }\end{array}$ \\
\hline $\begin{array}{l}\text { Présence enfant } \\
\text { 3- } 6 \text { ans }\end{array}$ & $\begin{array}{l}\text { Oui } \\
\text { Non }\end{array}$ & $\begin{array}{l}-9,375^{\star \star} \\
\text { Réf. }\end{array}$ & $\begin{array}{l}\text { 8,449* } \\
\text { Réf. }\end{array}$ & $\begin{array}{c}30,25^{\star \star \star} \\
\text { Réf. }\end{array}$ & $\begin{array}{c}18,72^{\star \star \star} \\
\text { Réf. }\end{array}$ & $\begin{array}{c}-4,697^{\star} \\
\text { Réf. }\end{array}$ & $\begin{array}{c}-10,50^{\star \star *} \\
\text { Réf. }\end{array}$ \\
\hline PCS & $\begin{array}{l}\text { Agriculteur } \\
\text { Artisan, commerçant } \\
\text { Profession libérale } \\
\text { Cadre } \\
\text { Prof. Intellect. ou art. } \\
\text { Enseignant } \\
\text { Prof. intermédiaire privé } \\
\text { Prof. Intermédiaire public } \\
\text { Technicien } \\
\text { Employé public } \\
\text { Police ou militaire } \\
\text { Employé administratif } \\
\text { Employé commerce - ser- } \\
\text { vices } \\
\text { Ouvrier qualifié } \\
\text { Ouvrier non qualifié }\end{array}$ & $\begin{array}{c}10,67 \\
9,758 \\
-27,72^{\star \star} \\
-4,844 \\
-12,45^{\star} \\
-24,79^{\star \star \star} \\
\text { Réf. } \\
-14,36^{\star} \\
-20,79^{\star \star \star} \\
-5,465 \\
-12,45 \\
-21,88^{\star \star \star} \\
-21,30^{\star \star \star} \\
-14,89^{\star \star} \\
-11,95\end{array}$ & $\begin{array}{l}4,814 \\
-12,15 \\
-11,53 \\
-15,48^{\star} \\
-17,72^{\star \star} \\
-21,52^{\star *} \\
\text { Réf. } \\
-19,13^{\star} \\
-9,253 \\
-5,736 \\
-30,63^{\star *} \\
-6,462 \\
-22,59^{\star \star} \\
-5,944 \\
-8,094\end{array}$ & $\begin{array}{c}-4,773 \\
-4,173 \\
-20,20 \\
-12,34 \\
-13,23 \\
-4,034 \\
\text { Réf. } \\
9,557 \\
7,918 \\
10,71 \\
35,11 \\
-3,743 \\
3,420 \\
-1,169 \\
29,39^{\star *}\end{array}$ & $\begin{array}{c}23,98^{\star \star} \\
-6,699 \\
5,546 \\
1,363 \\
8,382 \\
7,328 \\
\text { Réf. } \\
2,797 \\
4,607 \\
2,732 \\
-1,386 \\
14,75 \\
28,37^{\star *} \\
0,204 \\
-11,99\end{array}$ & $\begin{array}{c}20,37^{\star \star \star} \\
6,703 \\
10,60 \\
4,200 \\
18,71^{\star \star \star} \\
15,26^{\star \star \star} \\
\text { Réf. } \\
10,83^{\star \star} \\
12,14^{\star \star \star} \\
-3,888 \\
-4,857 \\
3,019 \\
9,245^{\star \star} \\
4,533 \\
5,748\end{array}$ & $\begin{array}{c}13,35 \\
6,049 \\
22,19^{\star \star \star} \\
8,421^{\star} \\
35,62^{\star \star \star} \\
26,39^{\star \star \star} \\
\text { Réf. } \\
30,11^{\star \star \star} \\
16,29^{\star \star \star} \\
1,115 \\
7,091 \\
13,55^{\star \star} \\
12,86^{\star \star} \\
3,798 \\
13,33^{\star \star}\end{array}$ \\
\hline Diplôme & $\begin{array}{l}\text { Sans } \\
\text { CEP BEPC } \\
\text { BEP CAP } \\
\text { Bac tech. } \\
\text { Bac général } \\
\text { Bac }+2 \\
\text { Supérieur Bac+2 }\end{array}$ & $\begin{array}{c}-11,43 \\
-7,258 \\
-9,675 \\
-4,389 \\
\text { Réf. } \\
\text { 1,899 } \\
-3,441\end{array}$ & $\begin{array}{c}4,622 \\
-2,304 \\
9,203 \\
10,42 \\
\text { Réf. } \\
6,738 \\
20,98^{\star \star}\end{array}$ & $\begin{array}{c}10,78 \\
11,97 \\
7,286 \\
14,20 \\
\text { Réf. } \\
10,02 \\
35,26^{\star \star \star}\end{array}$ & $\begin{array}{c}-5,250 \\
-18,38^{\star} \\
-7,222 \\
-14,34 \\
\text { Réf. } \\
-8,731 \\
-3,857\end{array}$ & $\begin{array}{l}-0,250 \\
8,255^{\star} \\
6,994^{\star} \\
9,705^{\star *} \\
\text { Réf. } \\
6,129 \\
6,643^{\star}\end{array}$ & $\begin{array}{c}-14,98^{\star \star \star} \\
-6,202 \\
-7,562 \\
-6,292 \\
\text { Réf. } \\
\text { 3,335 } \\
8,610^{\star}\end{array}$ \\
\hline Revenu par UC & & $-2,085$ & $-9,485^{\star \star \star}$ & $-3,158$ & $-1,919$ & $-0,818$ & 1,375 \\
\hline $\begin{array}{l}\text { Jour de vacances } \\
\text { scolaires }\end{array}$ & $\begin{array}{l}\text { Oui } \\
\text { Non }\end{array}$ & $\begin{array}{l}-1,828 \\
\text { Réf. }\end{array}$ & $\begin{array}{l}21,81^{\star \star \star} \\
\text { Réf. }\end{array}$ & $\begin{array}{c}-22,07^{\star \star \star} \\
\text { Réf. }\end{array}$ & $\begin{array}{c}-5,111 \\
\text { Réf. }\end{array}$ & $\begin{array}{l}\text { 0,0713 } \\
\text { Réf. }\end{array}$ & $\begin{array}{l}\text { 0,361 } \\
\text { Réf. }\end{array}$ \\
\hline Jour férié & $\begin{array}{l}\text { Oui } \\
\text { Non }\end{array}$ & $\begin{array}{l}\text { 10,01 } \\
\text { Réf. }\end{array}$ & $\begin{array}{l}0,468 \\
\text { Réf. }\end{array}$ & $\begin{array}{c}-56,96^{\star \star \star} \\
\text { Réf. }\end{array}$ & $\begin{array}{c}-3,079 \\
\text { Réf. }\end{array}$ & $\begin{array}{c}20,40^{\star \star \star} \\
\text { Réf. }\end{array}$ & $\begin{array}{l}\text { 8,145 } \\
\text { Réf. }\end{array}$ \\
\hline $\begin{array}{l}\text { Jour de la } \\
\text { semaine }\end{array}$ & $\begin{array}{l}\text { Jour de semaine hors mer- } \\
\text { credi et week-end } \\
\text { Mercredi } \\
\text { Samedi } \\
\text { Dimanche }\end{array}$ & $\begin{array}{l}\text { Réf. } \\
0,244 \\
13,77^{\star \star} \\
34,67^{\star \star *}\end{array}$ & $\begin{array}{l}\text { Réf. } \\
-8,616 \\
70,37^{\star \star \star} \\
74,46^{\star \star \star}\end{array}$ & $\begin{array}{c}\text { Réf. } \\
27,96^{\star \star} \\
-57,17^{\star \star \star} \\
-72,31^{\star \star \star}\end{array}$ & $\begin{array}{r}\text { Réf. } \\
12,17 \\
3,243 \\
-12,37^{\star \star}\end{array}$ & $\begin{array}{c}\text { Réf. } \\
-1,548 \\
40,56^{\star \star \star} \\
40,61^{\star \star \star}\end{array}$ & $\begin{array}{l}\text { Réf. } \\
-7,412 \\
33,58^{\star \star \star} \\
51,88^{\star \star \star}\end{array}$ \\
\hline
\end{tabular}


les mères: les soins aux enfants diminuent à mesure que les enfants grandissent alors que dans le même temps, les possibilités d'activités ludiques augmentent. La présence d'enfants est négativement corrélée avec le temps de loisir avec des amis et les loisirs avec ou sans amis. L'effet le plus prononcé en ce qui concerne cette dernière catégorie est certainement le fait d'être seul qui double le temps de loisir.

Un niveau de diplôme égal ou supérieur au $\mathrm{bac}+2$ est généralement associé à une plus grande sociabilité parents-enfants alors qu'un niveau d'éducation inférieur au bac va souvent de pair avec une sociabilité conjugale moindre. D'autre part, les femmes diplômées du supérieur passent plus de temps seules auprès de leurs enfants (près de 35 minutes un jour de semaine) que les autres mères. Ce résultat confirme en quelque sorte les travaux ethnographiques de Lareau (2003) qui montrent que les mères diplômés "investissent» dans le quotidien de leurs enfants (sorties, activités culturelles ou sportives, etc.) et contribuent ainsi directement à la reproduction sociale. $\mathrm{Ce}$ résultat est d'ailleurs conforté par le même effet positif d'un diplôme du supérieur sur le temps que les parents passent ensemble avec leurs enfants (+21 minutes). Le diplôme des pères est en revanche peu lié au temps qu'ils passent seuls auprès de leurs enfants.

Les loisirs et les sociabilités familiale et amicale récréative sont très fortement structurés par le rythme hebdomadaire. Les sociabilités conjugales et parents-enfants sont plus développées le samedi (respectivement 14 et 70 minutes supplémentaires) et plus encore le dimanche (respectivement 35 et 74 minutes supplémentaires) que le reste de la semaine. Il en va de même pour le temps de loisirs avec ou sans amis. Parallèlement, la sociabilité mère-enfants est plus forte le mercredi qu'un autre jour de semaine (environ 28 minutes en plus) et plus faible le samedi et plus encore le dimanche (respectivement environ 57 et 72 minutes en moins). L'effet du cycle hebdomadaire sur le temps père-enfant est beaucoup moins marqué, certainement en raison d'un niveau absolu plus faible d'implication auprès des enfants. Les temps mère- et père-enfant résultent très souvent de l'indisponibilité de l'autre parent et

Tableau 6 (suite)

\begin{tabular}{|c|c|c|c|c|c|c|c|}
\hline \multicolumn{2}{|c|}{$\begin{array}{l}\text { Variables } \\
\text { explicatives }\end{array}$} & \multirow{2}{*}{$\begin{array}{c}\text { Temps } \\
\text { conjugal }\end{array}$} & \multirow{2}{*}{$\begin{array}{c}\text { Temps } \\
\text { parents- } \\
\text { enfants }\end{array}$} & \multirow{2}{*}{$\begin{array}{c}\begin{array}{c}\text { Temps } \\
\text { mère- } \\
\text { enfants }\end{array} \\
-14,63^{\star \star \star ~}\end{array}$} & \multirow{2}{*}{$\begin{array}{c}\text { Temps } \\
\text { père- } \\
\text { enfants }\end{array}$} & \multirow{2}{*}{$\begin{array}{l}\begin{array}{l}\text { Loisirs } \\
\text { amis }\end{array} \\
-4,945^{\star \star \star}\end{array}$} & \multirow{2}{*}{$\begin{array}{c}\text { Loisirs } \\
\text { avec ou } \\
\text { sans amis } \\
-14,21^{\star * *}\end{array}$} \\
\hline $\begin{array}{l}\text { Nb heures travail } \\
\text { hors domicile }\end{array}$ & (Réf. : nb heures = 0) & & & & & & \\
\hline \multirow[t]{4}{*}{$\begin{array}{l}\text { NB heure travail } \\
\text { hors domicile } X\end{array}$} & $\begin{array}{l}\text { Jour de semaine hors } \\
\text { mercredi et week- end }\end{array}$ & Réf. & Réf. & Réf. & Réf. & Réf. & Réf. \\
\hline & Mercredi & $-0,915$ & 1,027 & $-4,341^{\star *}$ & $-1,783$ & $-0,131$ & 0,583 \\
\hline & Samedi & 0,184 & $-6,675^{\star \star \star}$ & $4,393^{\star \star}$ & $-1,346$ & $-3,406^{\star \star \star}$ & $-1,439^{*}$ \\
\hline & Dimanche & $-0,167$ & $-4,721^{\star \star \star}$ & $5,914^{\star *}$ & $-0,331$ & $-3,583^{\star \star \star}$ & $-1,293$ \\
\hline $\begin{array}{l}\mathrm{Nb} \text { heures travail } \\
\text { au domicile }\end{array}$ & (Réf. : nb heures $=0$ ) & $-4,405^{\star \star \star}$ & $-4,506^{\star \star}$ & $-10,75^{\star \star \star}$ & $-3,728^{\star \star}$ & $-5,039^{\star \star \star}$ & $-13,93^{\star \star \star}$ \\
\hline \multirow[t]{4}{*}{$\begin{array}{l}\text { Nb heures travail } \\
\text { au domicile } X\end{array}$} & $\begin{array}{l}\text { Jour de semaine hors } \\
\text { mercredi et week- end }\end{array}$ & Réf. & Réf. & Réf. & Réf. & Réf. & Réf. \\
\hline & Mercredi & 0,0343 & 3,079 & $11,43^{\star *}$ & 2,470 & $-0,731$ & 0,284 \\
\hline & Samedi & $5,316^{*}$ & 2,602 & 5,026 & 3,391 & $-7,774^{\star \star \star}$ & $-5,561^{\star \star \star}$ \\
\hline & Dimanche & $-0,252$ & 0,908 & 6,808 & 3,887 & $-6,485^{\star \star \star}$ & $-5,571^{\star \star \star}$ \\
\hline Constante & & $175,9^{\star \star \star}$ & $130,1^{\star \star \star}$ & $174,0^{\star \star \star}$ & $60,37^{\star \star \star}$ & $42,43^{\star \star \star}$ & $189,8^{\star \star \star}$ \\
\hline$N$ & & 10,515 & 6,582 & 3,814 & 3,739 & 13,360 & 13,360 \\
\hline $\mathrm{R} 2$ & & 0,240 & 0,173 & 0,231 & 0,107 & 0,157 & 0,296 \\
\hline R2 corrigé & & 0,24 & 0,167 & 0,22 & 0,095 & 0,153 & 0,234 \\
\hline
\end{tabular}

Note: les lignes qui correspondent aux interactions apparaissent en grisé dans le tableau. Les coefficients de certaines variables de contrôle (sexe, âge, et statut matrimonial) qui ne figurent pas dans le tableau sont disponibles sur demande auprès des auteurs. ${ }^{\star \star \star *} p<0,01 ;{ }^{* \star} p<0,05 ;{ }^{*} p<0,1$.

Lecture : toutes choses égales par ailleurs, la sociabilité parents- enfants est plus élevée de 74 minutes le dimanche qu'en semaine (hors mercredi et week- end), résultat statistiquement significatif (niveau de confiance supérieur à $99 \%$ ).

Champ : actifs occupés, France métropolitaine.

Source : enquête Emploi du temps 2009-2010, Insee. Calculs des auteurs. Résultats non pondérés. 
caractérisent avant tout les jours de semaine. Le temps de loisir en présence d'amis est également plus élevé le samedi et le dimanche (40 minutes en plus). Ces résultats mettent en relief non seulement l'importance du dimanche, mais également celle du samedi en tant qu'agents synchronisateurs de la famille et plus généralement de l'ensemble de la société (pas d'école et le plus souvent pas de travail).

Comme l'on pouvait s'y attendre, une heure de travail hors domicile un jour de semaine (hors mercredi et week-end) implique une réduction de toutes les composantes de la sociabilité familiale et en premier lieu du temps que les mères passent seules avec leurs enfants (- 14 minutes par heure de travail). Viennent ensuite les sociabilités amicale récréative et conjugale (respectivement - 14 minutes et - 8 minutes par heure de travail) et le temps parents-enfant (- 6 minutes par heure de travail). Ces impacts peuvent sembler faibles, mais il convient de les rapporter à une journée de travail de 8 heures pour saisir l'ampleur de la diminution : 60 minutes pour le temps conjugal (cf. tableau 7). Par ailleurs, il faut rapporter cette diminution à la sociabilité d'une journée non travaillée pour voir l'ampleur de cet effet : une journée de travail de 8 heures diminue de plus d'un tiers la sociabilité conjugale (34\%) et de $39 \%$ la sociabilité parents-enfants. Pour les autres catégories c'est encore plus élevé : $67 \%$ de temps mère-enfant de moins, $69 \%$ de temps père-enfants, littéralement annulation des loisirs avec les amis (- $93 \%$ ) et réduction de $60 \%$ du temps de loisirs total.

Le coefficient d'interaction entre le jour de la semaine et le nombre d'heures travaillées permet de tester l'hypothèse selon laquelle le travail le dimanche est plus lourd de conséquences pour la sociabilité qu'en semaine. Cette hypothèse est validée puisque le coefficient pour le temps parents-enfants est significatif. Le dimanche, la perte de sociabilité liée au travail hors domicile est bien amplifiée pour le temps parents-enfant (près de 5 minutes de sociabilité perdue en plus par heure travaillée) et pour le temps passé avec les amis (- 4 minutes en plus par heure travaillée). Ainsi, la perte de sociabilité parents-enfant est quasiment multipliée par deux lorsque la journée travaillée est le dimanche. Toutefois, nous avons vu qu'indépendamment du travail le dimanche, il y a ce jour-là un surcroît de sociabilités familiale et amicale récréative. Cette augmentation permet d'amortir les effets plus importants du travail dominical sur ces sociabilités. Il faut souligner qu'on trouve des résultats similaires pour le travail hors domicile le samedi qui est

Tableau 7

Durées estimées des différentes sociabilités selon le type de journée en semaine (hors mercredi) ou le dimanche et son statut (non travaillé, travaillé hors domicile)

\begin{tabular}{|c|c|c|c|c|c|c|}
\hline & \multicolumn{6}{|c|}{ en minutes / en \% } \\
\hline & $\begin{array}{l}\text { Temps } \\
\text { conjugal }\end{array}$ & $\begin{array}{l}\text { Temps } \\
\text { parents- } \\
\text { enfants }\end{array}$ & $\begin{array}{l}\text { Temps } \\
\text { mère- } \\
\text { enfants }\end{array}$ & $\begin{array}{l}\text { Temps } \\
\text { père- } \\
\text { enfants }\end{array}$ & $\begin{array}{l}\text { Loisirs } \\
\text { amis }\end{array}$ & $\begin{array}{l}\text { Loisirs } \\
\text { avec ou } \\
\text { sans amis }\end{array}$ \\
\hline $\begin{array}{l}\text { Sociabilité un jour de semaine (hors mercredi ) } \\
\text { non travaillé (en minutes) }\end{array}$ & 176 & 130 & 174 & 60 & 42 & 190 \\
\hline $\begin{array}{l}\text { Impact du travail (hors domicile) pendant } 8 \mathrm{~h} \\
\text { d'un jour de semaine (hors mercredi), en minutes }\end{array}$ & -60 & -51 & -117 & -42 & -40 & -114 \\
\hline en écart relatif (en \%) & -34 & -39 & -67 & -69 & -93 & -60 \\
\hline $\begin{array}{l}\text { Sociabilité nette d'un jour de semaine } \\
\text { (hors mercredi) travaillé hors domicile pendant } \\
8 \text { heures (en minutes) }\end{array}$ & 115 & 80 & 57 & 19 & 3 & 76 \\
\hline $\begin{array}{l}\text { Sociabilité d'un dimanche non travaillé } \\
\text { (en minutes) }\end{array}$ & 211 & 205 & 102 & 48 & 83 & 242 \\
\hline $\begin{array}{l}\text { Impact du travail le dimanche (hors domicile) } \\
\text { pendant } 8 \text { heures (en minutes) }\end{array}$ & -62 & -88 & -70 & -44 & -68 & -124 \\
\hline en écart relatif (en \%) & -29 & -43 & -69 & -92 & -82 & -51 \\
\hline $\begin{array}{l}\text { Sociabilité nette d'un dimanche travaillé } \\
\text { (hors domicile) pendant } 8 \text { heures (en minutes) }\end{array}$ & 149 & 116 & 32 & 4 & 15 & 118 \\
\hline
\end{tabular}

Lecture : toutes choses égales par ailleurs, la durée de la sociabilité parents- enfants nette d'un jour de semaine (hors mercredi) travaillé hors domicile pendant 8 heures est de 80 minutes : elle se décompose en 130 minutes (durée de sociabilité parents- enfants d'un jour de semaine (hors mercredi) non travaillé) auquel est soustrait l'impact de 8 heures de travail hors domicile un jour de semaine (hors mercredi), 51 minutes. Calculs à partir des résultats des estimations des modèles économétriques (tableau 5).

Champ : actifs occupés, France métropolitaine.

Source : enquête Emploi du temps 2009-2010, Insee. Calculs des auteurs. Résultats non pondérés. 
lui aussi un jour important pour les sociabilités parents-enfant et amicale récréative.

Il est possible de représenter graphiquement ces résultats. En effet, les modèles utilisés étant linéaires, ces effets prennent la forme de droites qui sont caractérisées par deux paramètres : 1'ordonnée à l'origine, ici le niveau de sociabilité lorsque la durée du travail est nulle, et le coefficient de détermination ou la pente de la droite, qui correspond à la diminution de sociabilité lorsque la durée du travail augmente d'une heure ${ }^{14}$.

La figure VII synthétise ces résultats pour la sociabilité conjugale. L'ordonnée à l'origine donne le niveau de sociabilité conjugale lorsque la durée du travail est nulle un jour de semaine : un peu moins de trois heures. La droite (trait plein) associée au travail hors domicile un jour de semaine indique que pour chaque heure travaillée la perte de sociabilité conjugale s'élève à un peu moins de 8 minutes. L'effet est le même lorsque le travail hors domicile intervient un dimanche : la seule différence est que le niveau de sociabilité ce jour-là est supérieur. Par contre chaque heure de travail diminue la sociabilité de la même durée qu'un jour de semaine (mais aussi le samedi ou le mercredi : toutes les droites ont en effet à peu près la même pente).

Il en va tout autrement pour la sociabilité parents-enfants. Pour un jour de semaine non travaillé, la durée de ce type de sociabilité s'élève à un peu plus de deux heures (voir la

14. Lorsque la pente est positive, elle indique l'augmentation de la sociabilité lorsque la durée du travail augmente d'une heure. À noter que l'ajout d'un terme quadratique, c'est-à-dire la durée de travail hors ou au domicile au carré, ne modifie pas de manière substantielle les résultats obtenus.

\section{Figure VII \\ Sociabilité conjugale prédite par le modèle selon la durée du travail hors domicile et le jour de la semaine}

Sociabilité conjugale prédite par le modèle (en minutes)

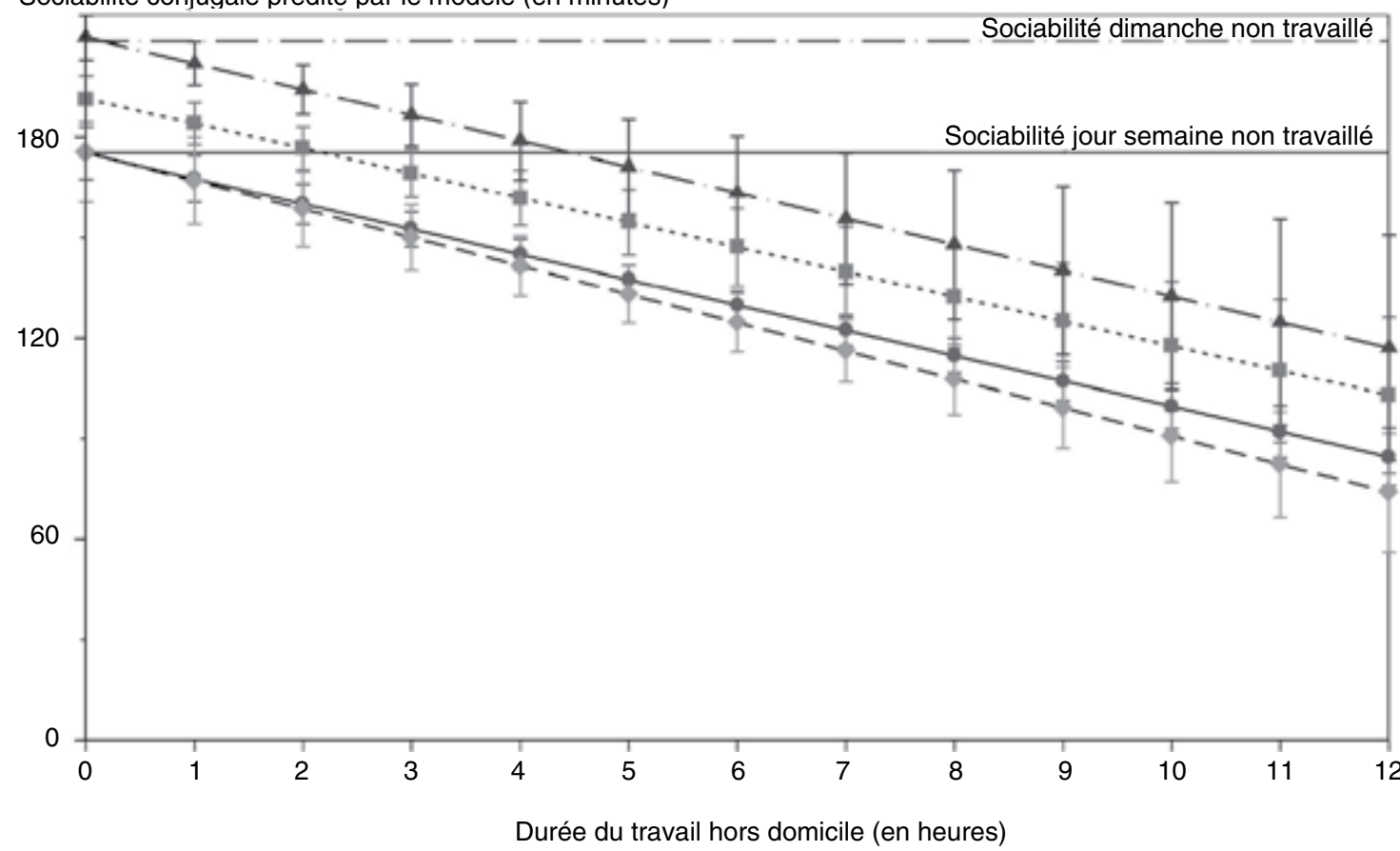

$\begin{array}{lll}\longrightarrow- & \text { Semaine hors mercredi } & -\rightarrow-- \text { Mercredi } \\ \cdots & & -\end{array}$

Lecture : toutes choses égales par ailleurs, la durée de la sociabilité conjugale nette d'un jour de semaine (hors mercredi) travaillé est de 115 minutes pour 8 heures de travail et de 100 minutes pour 10 heures de travail.Calculs à partir des résultats des estimations des modèles économétriques (tableau 5). Les estimations sont présentées avec leur intervalle de confiance à $95 \%$ qui sont matérialisés par les barres au milieu desquelles elles se trouvent.

Champ : actifs occupés, France métropolitaine.

Source : enquête Emploi du temps 2009-2010, Insee. Calculs des auteurs. Résultats non pondérés. 
droite horizontale de la figure VIII). L'effet synchronisateur du dimanche ajoute à cela $1 \mathrm{~h} 15$, ce qui fait que la sociabilité parents-enfants s'élève à près de $3 \mathrm{~h} 30 \mathrm{le}$ dimanche contre $2 \mathrm{~h}$ un jour de semaine. L'effet synchronisateur du samedi est également élevé (+70 minutes) comme relevé précédemment. Toute heure de travail hors domicile a pour effet de diminuer la sociabilité parents-enfants, un jour de semaine, d'un peu plus de 6 minutes. Lorsque ce travail prend place le dimanche, il faut ajouter 5 minutes à ces 6 minutes, ce qui se traduit donc par une perte de 11 minutes par heure travaillée à l'extérieur.

En termes de sociabilité parents-enfants, le travail dominical hors domicile a donc bien des effets supérieurs à ceux observés un jour de semaine. Plus la durée du travail hors domicile augmente, plus les droites associées aux sociabilité parents-enfants en semaine et le dimanche convergent : à partir de $8 \mathrm{~h}$ de travail, les niveaux prédits pour un jour de semaine et le dimanche ne sont plus statistiquement différents. Ce qui revient à dire que le niveau de sociabilité parents-enfants une journée de travail de $9 \mathrm{~h}$ le dimanche est le même que pour une journée de travail de $9 \mathrm{~h}$ en semaine : l'effet synchronisateur du dimanche disparaît complètement. Il convient également de remarquer que les effets négatifs du travail hors domicile sur la sociabilité parents-enfants sont du même ordre le samedi ${ }^{15}$ : chaque heure de travail s'accompagne d'une perte additionnelle de près de 7 minutes (par rapport à un jour de semaine), ce qui fait près de 13 minutes en moins par heure de travail. Il ne faut donc pas négliger le rôle que le samedi joue dans la synchronisation

15. Si le coefficient d'interaction est plus fort le samedi que le dimanche, cette différence n'est toutefois pas significative comme on le voit bien sur la figure (recouvrement des intervalles de confiance des deux séries d'estimateurs).

\section{Figure VIII \\ Sociabilité parents-enfants prédite par le modèle selon la durée du travail hors domicile et le jour de la semaine}

Sociabilité parents-enfants prédite par le modèle (en minutes)

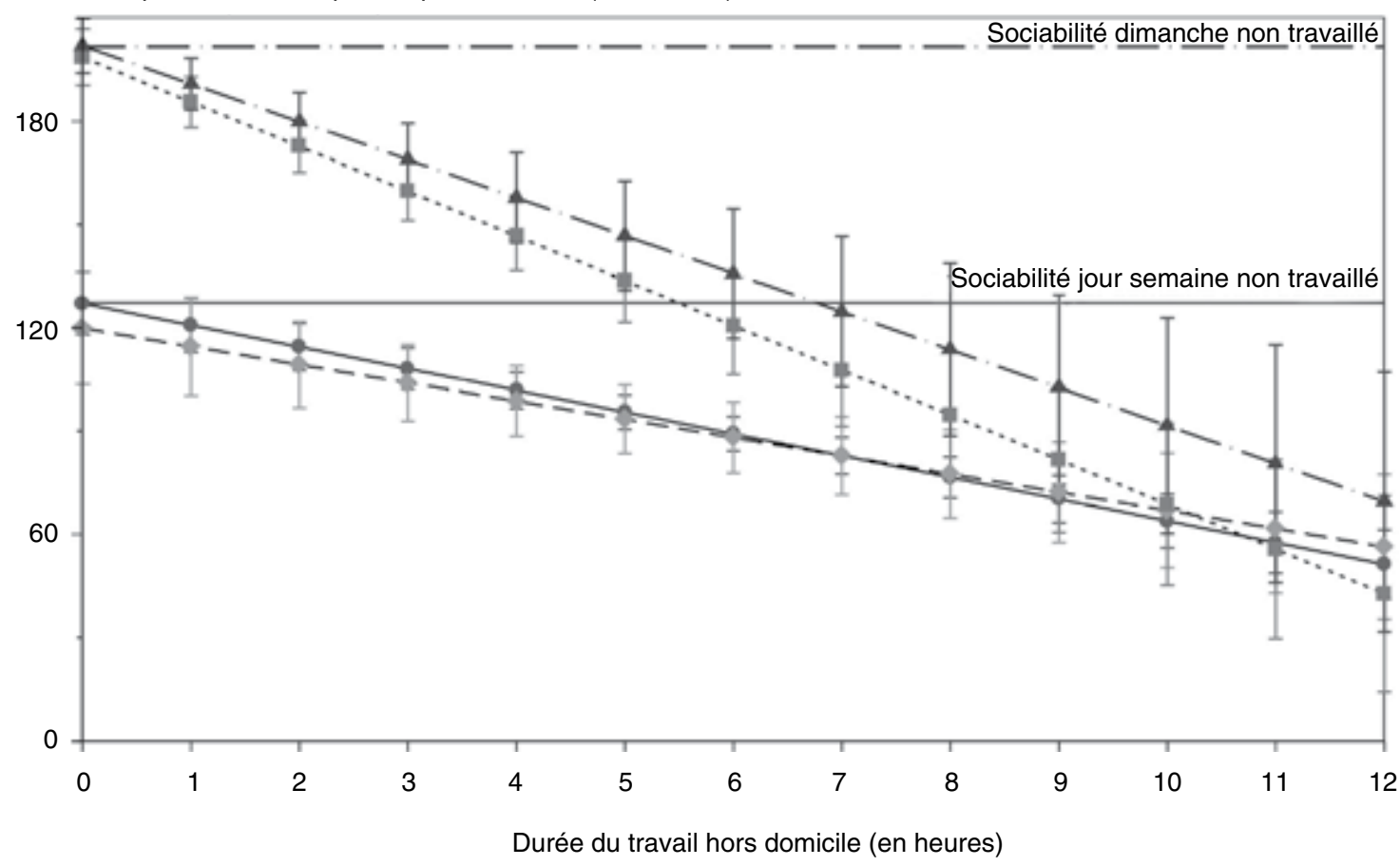

$\begin{array}{lll}\longrightarrow \ldots \text { Semaine hors mercredi } & -\rightarrow-- \text { Mercredi } \\ \ldots \ldots \text { Samedi } & -\Delta-\text { Dimanche }\end{array}$

Lecture: toutes choses égales par ailleurs, la durée des activités qui rassemblent parents et enfants est de 130 minutes un jour de semaine non travaillé. Calculs à partir des résultats des estimations des modèles économétriques (tableau 5). Les estimations sont présentées avec leur intervalle de confiance à $95 \%$ qui sont matérialisés par les barres au milieu desquelles elles se trouvent.

Champ : actifs occupés, France métropolitaine.

Source : enquête Emploi du temps 2009-2010, Insee. Calculs des auteurs. Résultats non pondérés. 
familiale, au même titre que le dimanche, en matière de temps parents-enfants ${ }^{16}$.

Selon les modèles, un dimanche travaillé de $8 \mathrm{~h}$ donne un temps parents-enfants de 116 minutes, contre 80 minutes un jour de semaine travaillé et 205 minutes un dimanche non travaillé. Un dimanche travaillé permet d'avoir plus de sociabilité parents-enfants qu'un jour de semaine mais moins qu'un dimanche non travaillé : la perte s'élève à $43 \%$ pour la sociabilité parents-enfants. Par rapport à un dimanche non travaillé, l'effet du travail du dimanche a également des conséquences sur le temps conjugal ( $29 \%$ en moins), sur le temps mère- et père-enfants (respectivement $70 \%$ et $92 \%$ en moins), sur les loisirs avec les amis ( $82 \%$ en moins) et sur les loisirs pris dans leur globalité dont la durée est divisée par deux $(51 \%)$ (cf. tableau 7).

Le nombre d'heures de travail à domicile un jour de semaine réduit également la sociabilité amicale récréative et familiale dans des proportions proches du travail hors domicile. Travailler à domicile réduit donc bien aussi la sociabilité familiale et amicale récréative. Toutefois, l'interaction montre que la perte de sociabilité familiale est la même un jour de semaine ou le dimanche (les interactions ne sont pas statistiquement significatives) : il n'y a pas d'aggravation dans le cas du travail dominical au domicile comme c'est le cas pour le travail hors domicile. En revanche, ce n'est pas le cas pour la sociabilité amicale récréative qui s'avère encore plus détériorée le dimanche qu'un jour de semaine. Cela apparait très logique puisque le travail à domicile implique, par définition, d'être chez soi : les autres membres de la famille ont plus de chance de s'y trouver que des amis. Le travail à domicile n'a donc pas du tout les mêmes conséquences sociales que le travail hors domicile. Dans certains cas, il n'a même aucune conséquence sur la sociabilité (temps passé avec le conjoint lorsque le travail à domicile intervient le samedi). Très logiquement, travailler à domicile implique de prendre du temps sur d'autres activités et notamment les loisirs qui se trouvent réduits, le dimanche, de 19 minutes par heure travaillée (contre 14 minutes un jour de semaine).

\section{De manière générale, les sociabilités perdues du fait du travail dominical ne sont pas récupérées avec la journée de repos compensateur}

Le report en semaine de la sociabilité perdue en raison du travail hors domicile le dimanche, se mesure au moyen du coefficient d'interaction. Comme l'on pouvait s'y attendre, on retrouve les résultats précédents, reformulés maintenant en termes de récupération (cf. figure IX) :

- pour les sociabilités conjugale et père-enfants, la perte de sociabilité consécutive au travail dominical est bien contrebalancée par la journée de repos compensateur ;

- pour les sociabilités parents-enfants et amicale récréative, la journée de repos compensateur ne permet pas de contrebalancer les effets négatifs du travail dominical. Le travail dominical engendre donc une perte nette (non compensée) de sociabilité parents-enfants et amicale récréative qui est très logiquement d'autant plus grande que le nombre d'heures travaillées est élevé ;

- pour le temps mère-enfant, le travail dominical se traduit bien par une baisse de sociabilité, mais celle-ci est plus que contrebalancée par la journée de repos compensateur.

Ce dernier résultat mérite des explications supplémentaires. L'effet de surcompensation de la journée de repos compensateur n'est pas lié au fait que la sociabilité mère-enfant un jour de semaine non travaillé est supérieure à un dimanche également non travaillé. L'effet de surcompensation est dû exclusivement au fait que la sociabilité mère-enfant diminue moins avec le travail le dimanche qu'un jour de semaine. L'hypothèse la plus vraisemblable serait que les mères qui travaillent le dimanche arrivent à préserver plus qu'en semaine le temps qu'elles passent seules avec leurs enfants. On peut faire l'hypothèse que ce sont les temps personnel et de loisirs auxquels les mères renoncent en semaine puisque, de manière générale, les durées de ces activités sont déjà moindres pour les femmes que pour les hommes (Brousse, 2015).

Ces résultats supplémentaires permettent également de mieux préciser ce qui fait la spécificité du dimanche. En effet, nous avons souligné jusqu'ici le rôle synchronisateur du dimanche (mais également du samedi, donc plus généralement du week-end) sans que nous ayons apporté d'autre justification à cette assertion en dehors du fait que ce jour-là il n'y pas d'école et que le travail rémunéré y est minoritaire. Or l'analyse des effets du travail dominical à travers le

16. Les travailleurs du dimanche sont également bien souvent des travailleurs du samedi. Ainsi, dans l'enquête Emploi du temps 2009-2010 trois travailleurs dominicaux sur quatre travaillent également le samedi. 
prisme de la compensation apporte des éléments supplémentaires qui confortent l'hypothèse de ce rôle synchronisateur. En effet, aux types de sociabilités distingués ici sont associés des besoins de synchronisation de nature différente. De manière générale, plus le nombre de personne à synchroniser est faible, plus la synchronisation s'en trouve facilitée; par ailleurs, plus les personnes à synchroniser sont proches spatialement (par exemple elles partagent le même logement), plus il est facile de les réunir.

À une exception près, on retrouve cette logique dans les effets du repos compensateur observés empiriquement. D'un côté, la journée de repos compensateur permet de contrebalancer la sociabilité perdue pour les groupes d'interactions dont la synchronisation est la plus aisée (deux personnes ou catégories d'acteurs, partageant le même domicile: conjoints ou père et enfant(s)), de l'autre, elle ne permet de le faire qu'imparfaitement pour les groupes d'interactions dont la synchronisation est moins facile (plus de deux personnes qui résident dans le même logement ou bien deux personnes qui habitent dans des lieux différents : parents et enfant(s) ou amis). L'effet synchronisateur du dimanche apparaît donc très nettement puisque plus les sociabilités sont exigeantes en termes de co-présence, moins la journée de repos compensateur permet de contrebalancer complètement les effets du travail dominical.

Enfin, le travail dominical a des conséquences substantielles sur la sociabilité. Les pertes de sociabilités induites par le travail dominical, malgré leur compensation par une journée de repos compensateur sont importantes : relativement à la sociabilité totale correspondant à la configuration de référence (dimanche non travaillé et jour de semaine (hors mercredi) travaillé), les pertes de sociabilités parents-enfant et amicale récréative, s'élèvent à, respectivement, $15 \%$ et $30 \%$ en supposant une journée

\section{Figure IX \\ Pertes (ou gains) nettes (nets) de sociabilité compensées par le repos compensateur pour un dimanche travaillé hors domicile pour chacune des sociabilités considérées}

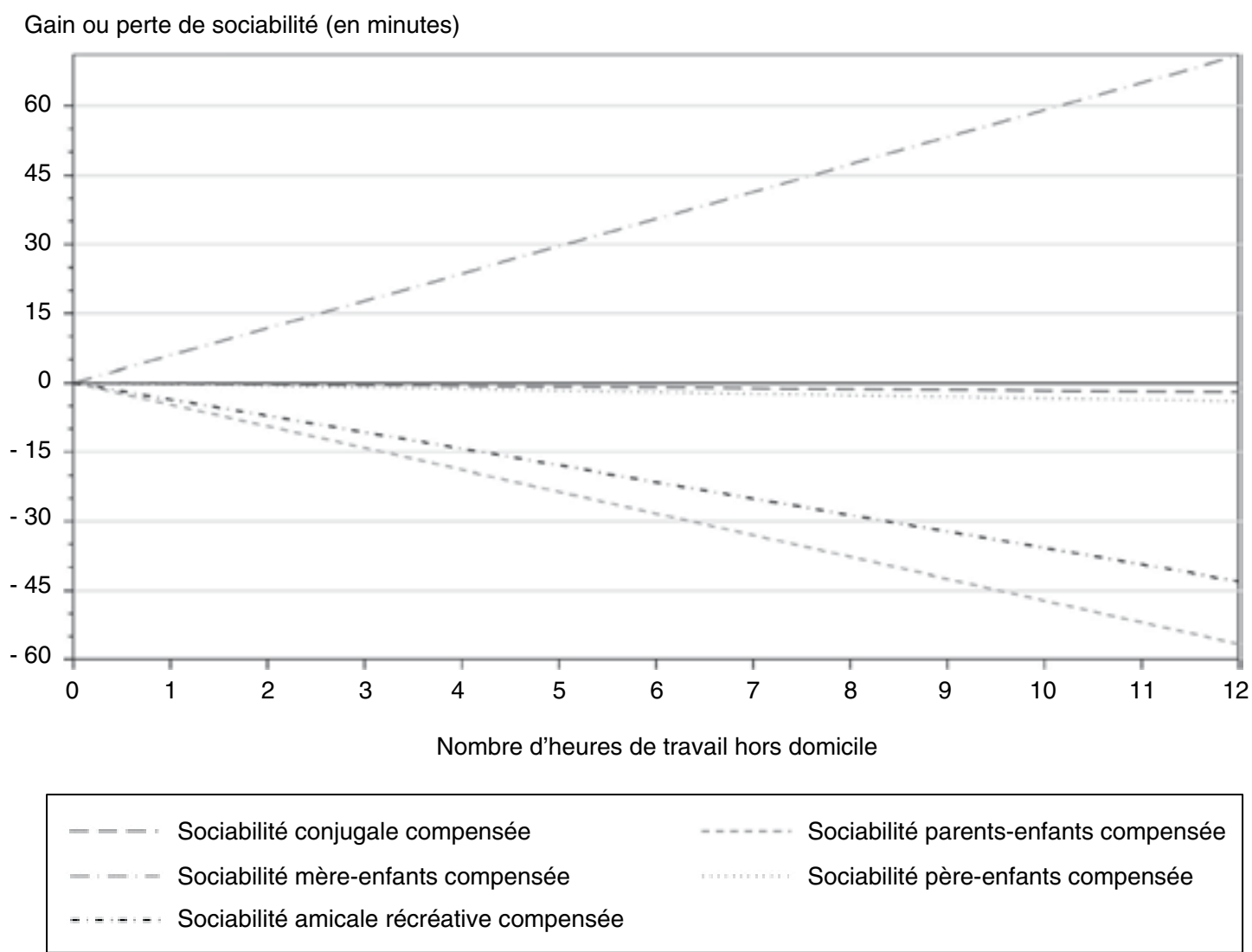

Lecture : toutes choses égales par ailleurs, la perte nette de sociabilité parents-enfants est de 30 minutes pour un peu plus de 6 h de travail le dimanche, après compensation.

Champ : actifs occupés, France métropolitaine.

Source : enquête Emploi du temps 2009-2010, Insee. Calculs des auteurs. Résultats non pondérés. 
de travail de 8 heures par rapport à la configuration de référence (cf. figure $\mathrm{X}$ ).

Selon nos estimations économétriques, la perte de sociabilité liée au travail hors domicile le dimanche est loin d'être systématiquement récupérée par une plus grande sociabilité grâce à la journée de repos compensateur : une partie substantielle des temps de sociabilités parents-enfants et amicale récréative perdus les dimanches ne sont pas récupérés pendant la semaine et correspondent à des pertes nettes pour les travailleurs dominicaux.

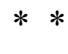

Le dimanche n'est toujours pas un jour comme un autre : il est avant tout le jour de la famille, des amis et des loisirs. Jour sans école et sans travail pour une majorité des salariés, il fournit à la famille et à son environnement social un espace temporel propice aux relations. Les loisirs familiaux, en forte augmentation depuis le milieu des années 1980, sont l'un des supports quotidiens des liens conjugaux et familiaux (Lesnard, 2009). À ce titre, l'effet synchronisateur du dimanche joue en faveur de la sociabilité familiale récréative et du renforcement de ces liens.

Cet effet est contrecarré par le travail le dimanche. Il réduit les sociabilités familiales et amicales récréatives de ceux qu'il concerne. Pour les sociabilités parents-enfants et amicales récréatives, cette diminution va au-delà de celle que le travail induit un jour de semaine et n'est pas compensée par les sociabilités qui se développent un jour de repos en semaine. Cette perte

\section{Figure $\mathrm{X}$ \\ Pertes nettes relatives de sociabilité parents-enfants et amicale récréative, compensées par le repos compensateur pour un dimanche travaillé hors domicile}

Perte de sociabilité (en \%)

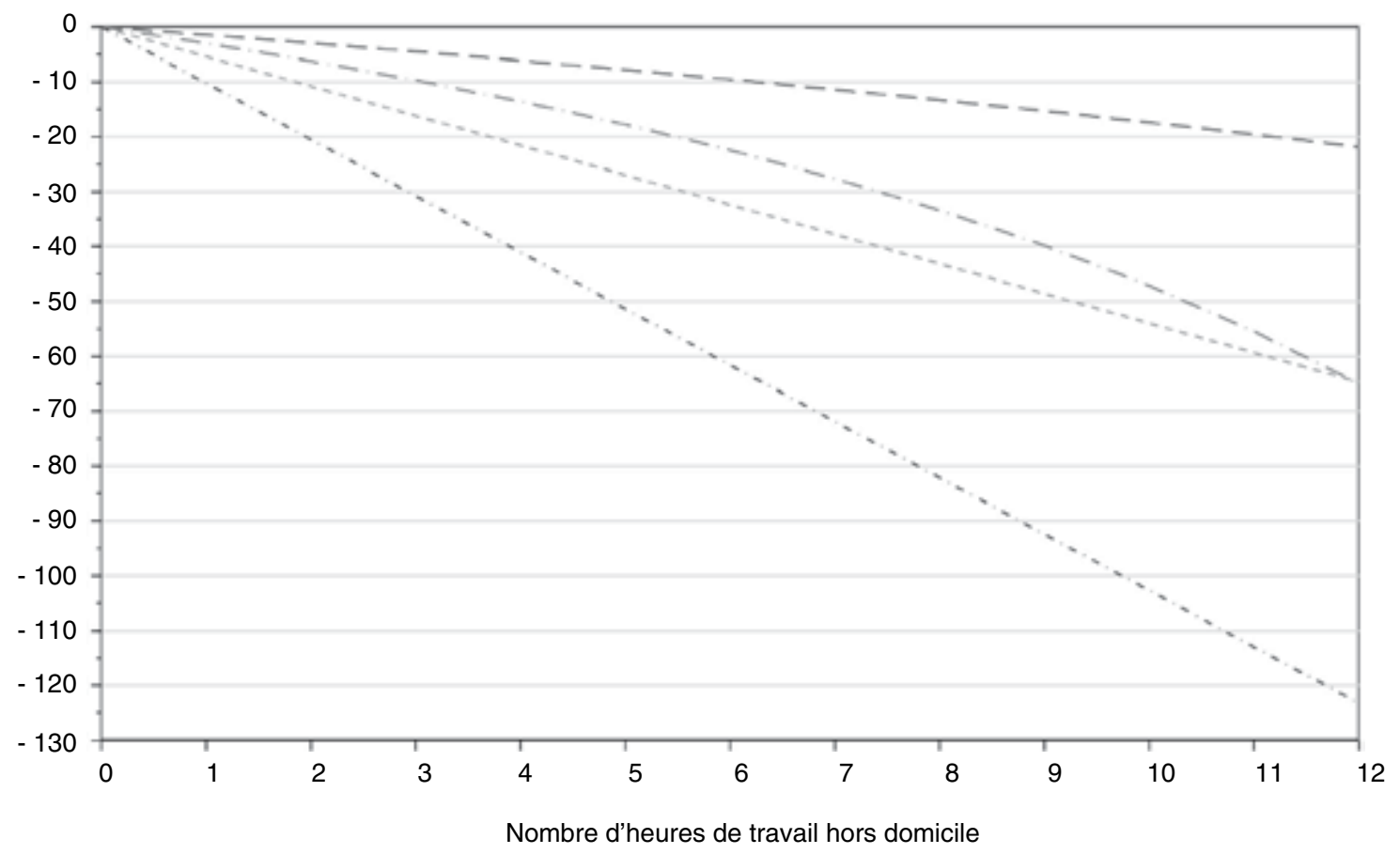

$$
\begin{aligned}
& \text { - - Sociabilité parents-enfants compensée _ _..... Sociabilité parents-enfants non compensée } \\
& \text { _- - Sociabilité amicale récréative compensée _ _. - - - Sociabilité amicale récréative non compensée }
\end{aligned}
$$

Lecture: toutes choses égales par ailleurs, la perte nette (de la compensation) de sociabilité amicale récréative est de $30 \%$ pour $8 \mathrm{~h}$ de travail le dimanche par rapport à la configuration de référence (dimanche non travaillé et jour de semaine (hors mercredi) travaillé pendant 8 heures).

Champ : actifs occupés, France métropolitaine.

Source : enquête Emploi du temps 2009-2010, Insee. Calculs des auteurs. Résultats non pondérés. 
de sociabilité pose la question des autres effets à plus long terme. Dans la mesure où, selon des études réalisées dans d'autres pays, les horaires atypiques accroissent les risques de conflits familiaux et de séparation (Täht et Mills, 2015 ; White et Keith, 1990), le travail dominical hors domicile, qui est une forme d'horaire atypique, pourrait avoir également dans notre pays des conséquences similaires à moyen terme sur le lien familial. Le développement de données longitudinales, encore insuffisant en France, permettrait de confirmer ce constat. En outre, le travail le dimanche hors domicile réduit considérablement la sociabilité amicale récréative.

Enfin, le travail le dimanche touche principalement certains groupes sociaux : forces de police, armée, hôpitaux, mais aussi ouvriers des industries de process et employés du commerce et des services. Dans les deux derniers cas, ce sont donc principalement des salariés faiblement qualifiés du bas de l'espace socioéconomique qui se trouvent concernés par le travail dominical. Travailler le dimanche est également corrélé à de mauvaises conditions temporelles de travail, notamment une faible autonomie temporelle ainsi qu'une prévisibilité du travail réduite. Plus généralement, le travail dominical s'inscrit le plus souvent dans des rythmes de travail hebdomadaires atypiques: semaines avec journées décalées la nuit ou le matin, semaines fragmentées ou encore longues semaines de travail. Le travail dominical n'est ainsi le plus souvent qu'une des facettes des horaires de travail atypiques. Ses conséquences sur la sociabilité familiale et amicale récréative ainsi que sur les lois sont plus importantes puisque les horaires atypiques en semaine sont également source de désynchronisation des horaires de travail et d'une moindre sociabilité familiale (Lesnard, 2009).

\section{BIBLIOGRAPHIE}

Artus P., Cahuc P. et Zylberberg A. (2007), Temps de travail, revenu et emploi, La Documentation française, Paris.

Bailly J.-P. (2013), Rapport sur la question des exceptions au repos dominical dans les commerces : vers une société qui s'adapte en gardant ses valeurs, Premier ministre, Paris.

Beck R. (1997), Histoire du dimanche de $1700 \grave{a}$ nos jours, Editions de l'Atelier, Paris.

Beffy M., Fougère D. et Maurel A. (2009), "L'impact du travail salarié des étudiants sur la réussite et la poursuite des études universitaires ", Économie et Statistique, ${ }^{\circ}$ 422, pp. 31-50.

Berger P. et Kellner H. (1964), « Marriage and the construction of reality: an exercise in the microsociology of knowledge $»$, Diogenes, ${ }^{\circ} 46$, pp. 1-24.

Bittman M. (2005), « Sunday working and family time », Labour \& Industry, n 16 , pp. 59-81.

Brousse C. (2015), «La vie quotidienne en France depuis 1974. Les enseignements de l'enquête Emploi du temps ", Économie et Statistique, $\mathrm{n}^{\circ}$ 478-479-480, pp. 79-117.
Cabantous A. (2013), Le dimanche, une histoire: Europe occidentale (1600-1830), Seuil, Paris.

Castell L. (2014), «Le week-end reste un temps de partage et de repos », France Portrait Social, pp. 97-108.

Cette G., Cunéo P., Herbay J.-P. et Preel B. (1992), «L'impact de l'ouverture des commerces le dimanche », Travail et emploi, n ${ }^{\circ}$ 51, pp. 98-111.

Cette G., Morel F. et Sylvain A. (2014), Comment relancer l'emploi dans le commerce de détail ?, Alliance du commerce, Paris.

Chenu A. et Lesnard L. (2006), "Time Use Surveys: a Review of their Aims, Methods, and Results », European Journal of Sociology, n ${ }^{\circ}$ 47, pp. 335-359.

Daly K. J. (1996), Families \& Time. Keeping Pace in a Hurried Culture, Sage, Thousand Oaks.

Daly K. J. (2001), « Deconstructing Family Time: From Ideology to Lived Experience », Journal of Marriage and Family, n ${ }^{\circ} 63$, pp. 283-294.

Dantec R. (2008), Le dimanche, Ouest-France éditions, Rennes. 
Dumazedier J. (1962), Vers une civilisation $d u$ loisir?, Seuil, Paris.

Gelman A. et Hill J. (2007), Data analysis using regression and multilevel/hierarchical models, Cambridge University Press, Cambridge/ New York.

Gershuny J. (2000), Changing Times: Work and Leisure in Postindustrial Society, Oxford University Press, Oxford.

Hall E. T. (1983), The Dance of Life: The Other Dimension of Time, Anchor Press/Doubleday, Garden City.

Harline C. (2007), Sunday: A History of the First Day from Babylonia to the Super Bowl, Doubleday Religion, New York.

Jaccard J. et Turrisi R. (2003), Interaction effects in multiple regression, Sage Publications, Thousand Oaks (CA).

Lareau A. (2003), Unequal childhoods: class, race, and family life, University of California Press, Berkeley.

Lesnard L. (2008), «Off-Scheduling within Dual-Earner Couples: An Unequal and Negative Externality for Family Time », American Journal of Sociology, $\mathrm{n}^{\circ}$ 114, pp. 447-490.

Lesnard L. (2009), La famille désarticulée. Les nouvelles contraintes de l'emploi du temps, PUF, Paris.

McCrossen A. (2000), Holy day, holiday: the American Sunday, Cornell University Press, Ithaca.

Michelson W. (2010), " Time use on sundays in Canada over time and by jurisdiction in view of changing policies on Sunday opening », IATUR Conference.

Miller S. (2008), The peculiar life of Sundays, Harvard University Press, Cambridge (MA).

Moati P. et Pouquet L. (2008), « L'ouverture des commerces le dimanche : opinions des français, simulation des effets ", Cahier de recherche, $\mathrm{n}^{\circ} 246$.

Perron D. (2010), Histoire du repos dominical : un jour pour faire société, L'Harmattan, Paris.

Perrot A. (2015), Réforme du travail dominical, France Stratégie, Paris.
Ponthieux S. (2015), « Les enquêtes Emploi du temps : une source majeure pour l'étude des inégalités sociales et de genre », Économie et Statistique, $\mathrm{n}^{\circ}$ 478-479-480, pp. 59-77.

Reynié D. (2009), « Travailler le dimanche : qu'en pensent ceux qui travaillent le dimanche?», Sondage, analyse, synthèse : éléments pour le débat, Fondapol, Paris.

Rinderspacher J., Henckel D. et Hollbarch B. (1994), Die Welt am Wochenende. Entwicklungsperspektiven der Wochenruhetage - ein interkultureller Vergleich, SWI Verlag, Bochum.

Rybczynski W. (1991), Histoire $d u$ week-end, Liana Levi, Paris.

Saint Pol T. de (2006), « Le dîner des Français : un synchronisme alimentaire qui se maintient », Économie et Statistique, ${ }^{\circ} 400$, pp. 45-69.

Sautory O. et Zilloniz S. (2015), « De l'organisation des journées à l'organisation de la semaine : des rythmes de travail socialement différenciés », Économie et Statistique, n 478-479-480, pp. 155-188.

Singly F. de (1996), Le soi, le couple et la famille, Nathan, Paris.

Stewart J. (2012), Tobit or Not Tobit, BiblioGov, Washington.

Szalai A. (1972), The Use of Time. Daily Activities of Urban and Suburban Populations in Twelve Countries, Mouton, The Hague, Paris.

Täht K. et Mills M. (2015), Out of Time: The Consequences of Non-standard Employment Schedules for Family Cohesion, Springer, Dordrecht.

Vinck L. et Algava É. (2012), « En 2011, $29 \%$ des salariés ont travaillé le dimanche de manière habituelle ou occasionnelle ", Dares analyses, $\mathrm{n}^{\circ} 75$.

White L. et Keith B. (1990), "The effect of shift work on the quality and stability of marital relations », Journal of Marriage and the Family, $\mathrm{n}^{\circ} 52$, pp. 453-462.

Winship C. et Radbill L. (1994), « Sampling Weights and Regression Analysis ", Sociological Methods \& Research, ${ }^{\circ} 23$, pp. 230-257.

Young M. D. et Willmott P. (1973), The symmetrical family. A study of work and leisure in 
the London region, Routledge and Kegan Paul, London.

Zeruvabel E. (1985), The Seven Day Circle. The History and Meaning of the Week, The Free Press, New York.

Zeytinoglu I. U. et Cook G. B. (2006), «Who is working at weekends in Canada?», dans
Decent Working Time: New Trends, New Issues, (Boulin J.-Y., Lallement M., Messenger J. C. et Michon F. dir.), International Labour Office, Genève, pp. 395-415.

Zuzanek J. et Smale B. J. A. (1999), « Life-Cycle and Across-the-Week Allocation of Time to Daily Activities ", Time Use Research in the Social Sciences, pp. 127-153. 